\title{
Review \\ Laser Powder Bed Fusion of Unalloyed Tungsten: A Review of Process, Structure, and Properties Relationships
}

\author{
Mahmoud S. Seyam *(D), Philip Koshy and Mohamed A. Elbestawi \\ Department of Mechanical Engineering, McMaster University, Hamilton, ON L8S 4L7, Canada; \\ koshy@mcmaster.ca (P.K.); elbestaw@mcmaster.ca (M.A.E.) \\ * Correspondence: seyamm@mcmaster.ca
}

check for updates

Citation: Seyam, M.S.; Koshy, P.; Elbestawi, M.A. Laser Powder Bed Fusion of Unalloyed Tungsten: A Review of Process, Structure, and Properties Relationships. Metals 2022, 12, 274. https://doi.org/10.3390/ met12020274

Academic Editor: Marco Mandolini

Received: 23 December 2021

Accepted: 31 January 2022

Published: 2 February 2022

Publisher's Note: MDPI stays neutral with regard to jurisdictional claims in published maps and institutional affiliations.

Copyright: (C) 2022 by the authors. Licensee MDPI, Basel, Switzerland. This article is an open access article distributed under the terms and conditions of the Creative Commons Attribution (CC BY) license (https:// creativecommons.org/licenses/by/ $4.0 /)$.

\begin{abstract}
Tungsten (W) as a structural component has grown roots in many special applications owing to its radiation-shielding capabilities and its properties at elevated temperatures. The high ductile-brittle transition temperature (DBTT) and the very high melting point of tungsten however have limited its processability to certain technologies such as powder metallurgy. Laser powder bed fusion (LPBF) has been introduced in recent years as an alternative for manufacturing tungsten parts to overcome the design limitations posed by powder metallurgy technology. A review of the literature shows significant improvements in the quality of tungsten components produced by LPBF, implying a strong potential for manufacturing tungsten with this technology and a need for further research on this subject. This review paper presents the current state-of-the-art in LPBF of unalloyed tungsten, with a focus on the effect of process parameters on the developed structure/properties and identifies current knowledge gaps.
\end{abstract}

Keywords: additive manufacturing; balling; cracking; microstructure; porosity; powder bed fusion; powder metallurgy; refractory metals; selective laser melting; tungsten

\section{Introduction}

Tungsten $(\mathrm{W})$ in its unalloyed form has been used as a structural component in a variety of applications including fusion reactors, heat exchangers, rocket engines, blast furnaces, and ammunition [1-9]. The unique properties of unalloyed tungsten including its exceptionally high melting temperature $\left(\approx 3422{ }^{\circ} \mathrm{C}\right)$, good thermal conductivity $(\approx 173 \mathrm{~W} / \mathrm{mK})$, and low thermal expansion coefficient $(\approx 4.49 \mu \mathrm{m} / \mathrm{mK})$ are of significant importance for the mentioned applications $[10,11]$. Tungsten is also a very dense metal $\left(\approx 19.3 \mathrm{~g} / \mathrm{cm}^{3}\right)$ with $\mathrm{X}$-ray attenuation characteristics that are comparable to lead $(\mathrm{Pb})[12,13]$, thus making it useful as an electron target in x-ray tubes, collimators in radiosurgery, anti-scatter grids in CT scanners, and radiation shields in nuclear applications [14-18].

Bulk tungsten parts have conventionally been produced by solid state sintering via powder metallurgy technology following the process of chemical extraction of the metal powder from its minerals [19]. The sintering process often requires post-densification operations such as mechanical working, hot isostatic pressing (HIP) or post-infiltration in order to reduce the inherent porosity in sintered parts $[10,20,21]$. A recent trend in consolidating unalloyed tungsten powder is the use of laser powder bed fusion LPBF, given the ability to fully melt it using laser energy [22]. Another advantage is the significant shape versatility offered by LPBF relative to compaction molds used in powder metallurgy.

Despite the several publications that have focused on utilizing LPBF to produce unalloyed tungsten, little effort has been expended to summarize what has been achieved so far. Only one related review, to the best of the present authors' knowledge, was published with focus on classifying the crack/porosity suppression methods in LPBF of tungsten [23]. The published literature however still lacks a review that compiles the reported process windows/maps and the related microstructural and physical properties. 
A preliminary search for references was conducted on google scholar using the keywords: tungsten, laser powder bed fusion, and selective laser melting. Additional subtopics such as microstructure defects, process maps, properties, and applications were also included in the preliminary search. Recent publications with direct relevance to the subject of LPBF of unalloyed tungsten were then identified. Following a snowball approach, additional sources were also obtained from the cited references in each publication. Reported data from each reference with relevance to tungsten powder production and characterization, process maps for LPBF of tungsten, and microstructure/properties of the consolidated powder have been collected, evaluated, and organized in one coherent construction. References for established concepts were also included wherever needed in the present context.

This review paper provides a reference for researchers on the current state-of-the-art in LPBF of unalloyed tungsten following a process-structure-properties paradigm. The next section (2. Process) begins with a description of the LPBF process, followed by a comparative review of the reported feedstock/substrate characteristics and the available process maps. The subsequent section (3. Structure) covers the expected microstructure of the LPBF printed parts as reported in the literature with an emphasis on the influence of process parameters on common microstructural defects. The paper also covers the expected physical properties in a separate section (4. Properties) and concludes with a summary (5. Summary and Outlook) of the main findings as well as the knowledge gaps in the literature. The final section of this paper also includes a discussion of the present and foreseen applications of unalloyed tungsten as manufactured by LPBF.

\section{Process}

The production of tungsten 3D parts by Laser powder bed fusion LPBF is done by full melting of tungsten powder in a layer-by-layer fashion. A powder layer with a predefined thickness $(t)$ is spread over the substrate (building platform) followed by selective laser melting along a predefined path generated by computer software. Upon solidification, each consolidated layer then serves as a new substrate for the subsequent powder layer Figure 1a. The process repeats in this fashion until the entire component is built [24-26]. Figure $1 \mathrm{~b}$ shows the process parameters in the LPBF process.

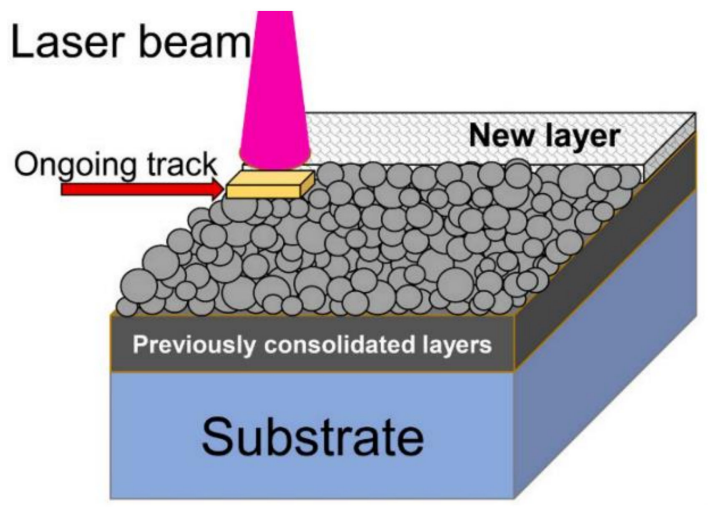

(a)

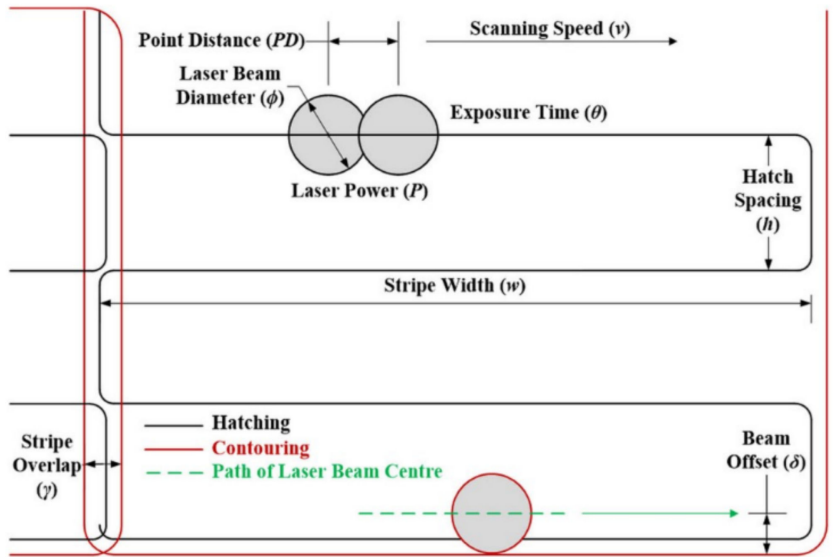

(b)

Figure 1. (a) Schematic drawing of the LPBF process [25]; (b) main process parameters in LPBF [26].

\subsection{Selection of Feedstock and Substrate}

\subsubsection{Feedstock}

Tungsten metal powder (feedstock) is extracted from its oxides $\left(\mathrm{WO}_{3}\right.$ and $\left.\mathrm{WO}_{3-\mathrm{x}}\right)$ by hot hydrogen reduction [10]. Process parameters such as humidity and temperature are controlled during the reduction process to produce powder particle sizes between 0.1 and 
$10 \mu \mathrm{m}$. Other extraction techniques (doped oxides) are also used to produce larger particle sizes up to $100 \mu \mathrm{m}$. The resulting morphology of as-extracted powder, often referred to as irregular powder, is shown in Figure 2 [10].

The irregular powder has been utilized as feedstock at the beginnings of LPBF of tungsten [27-33]. The maximum achieved densities however could not exceed $96.5 \%$ of theoretical density [33], which could be attributed to the fact that such powders were originally tailored for processing via powder metallurgy techniques (pressing, sintering, etc.,). Unlike powder metallurgy, production of unalloyed tungsten via LPBF involves spreading of thin layers of powder $(<50 \mu \mathrm{m}$ [18]) over the substrate or the previous layer.

The flowability of tungsten powder is therefore of significant importance to ensure uniform distribution of the powder in the layer. Wang et al. [34] studied the effect of radio frequency $(\mathrm{RF})$ plasma spheroidization of irregular tungsten powder. They reported improvements in powder flowability and packing density by $(60 \%)$ and $(104 \%)$ respectively after spheroidization. The increase in flowability of spherical powder was attributed to the absence of the crystal facets, Figure 2, which are normally present in irregular powder, and contribute to particle clogging [10,32,34].

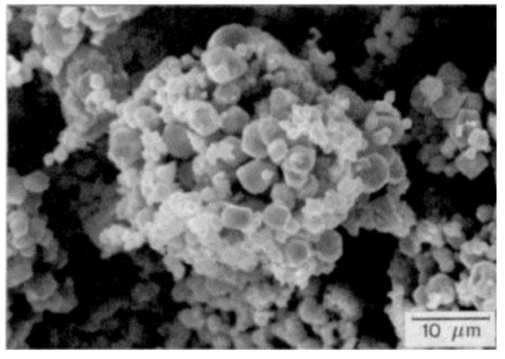

(a)

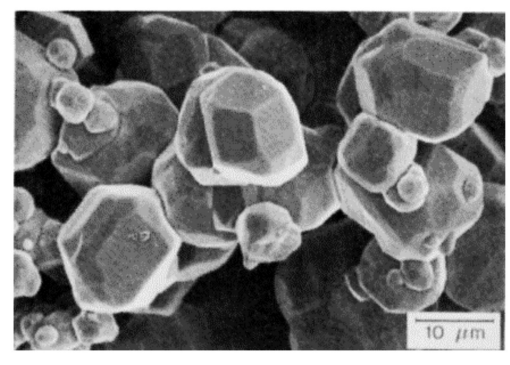

(b)

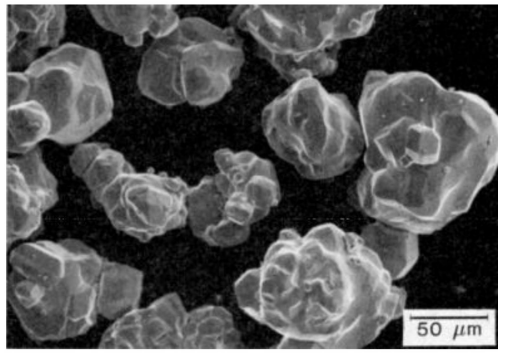

(c)

Figure 2. Irregular tungsten feedstock: (a) small size $(<10 \mu \mathrm{m})$ loosely agglomerated W powder obtained by hydrogen reduction at low temperature and humidity; (b) medium size (10-25 $\mu \mathrm{m}) \mathrm{W}$ powder obtained by hydrogen reduction at high temperature and humidity; (c) large size (25-100 $\mu \mathrm{m})$ W powder obtained by lithium doping [10].

The spheroidization of irregular powder also improves stacking of particles upon each other and results in a noticeable increase in powder packing density as well as the final solid part density [34,35]. The adoption of spherical powder particles instead of irregular ones has led to more than a $4 \%$ increase in relative density at optimum process parameters as reported by $\mathrm{Zi}$ et al. [32] (Figure 3). Wang et al. [34] have also reported a reduction in lack of fusion porosity when using spherical powder instead of irregular powder under same process parameters (Figure 4). Relative densities of unalloyed tungsten above $98 \%$ have been recently achieved by LPBF of spherical powder feedstock [36-45].

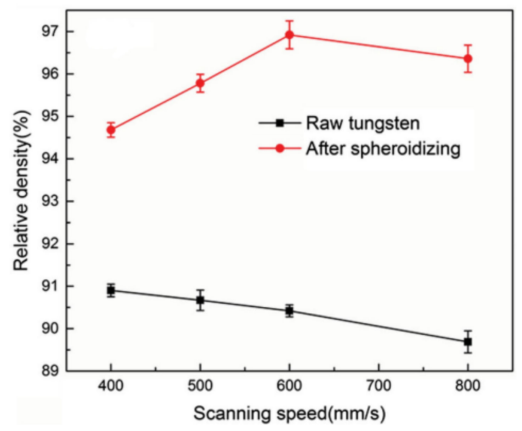

(a)

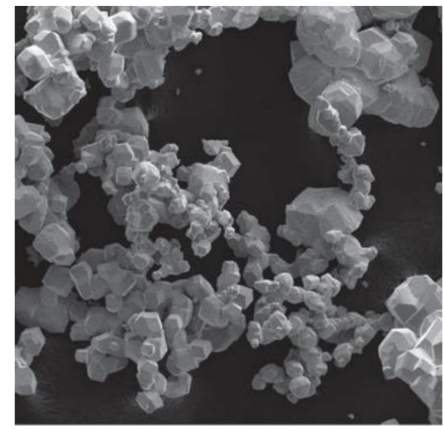

(b)

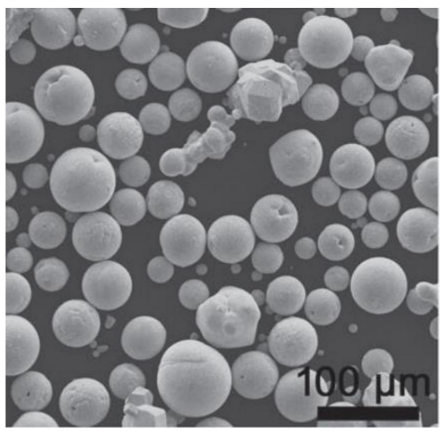

(c)

Figure 3. (a) Influence of $\mathrm{W}$ feedstock particle shape on the produced relative density, (b) irregular powder particles, (c) spherical powder particles [32]. 
The research on RF plasma spheroidization of tungsten powder has also revealed favorable effect on powder particle size as reported by Zi et al. [32] and Wang et al. [31]. Particle size measurements done by Zi et al. [32] after spheroidization of irregular tungsten powder have shown a reduction in average diameter by $50.5 \%$, which led to a significant increase in packing density. The size reduction of powder particles after RF plasma spheroidization has also resulted in an overall increase of the exposed surface area and improved the laser energy absorption by powder particles.

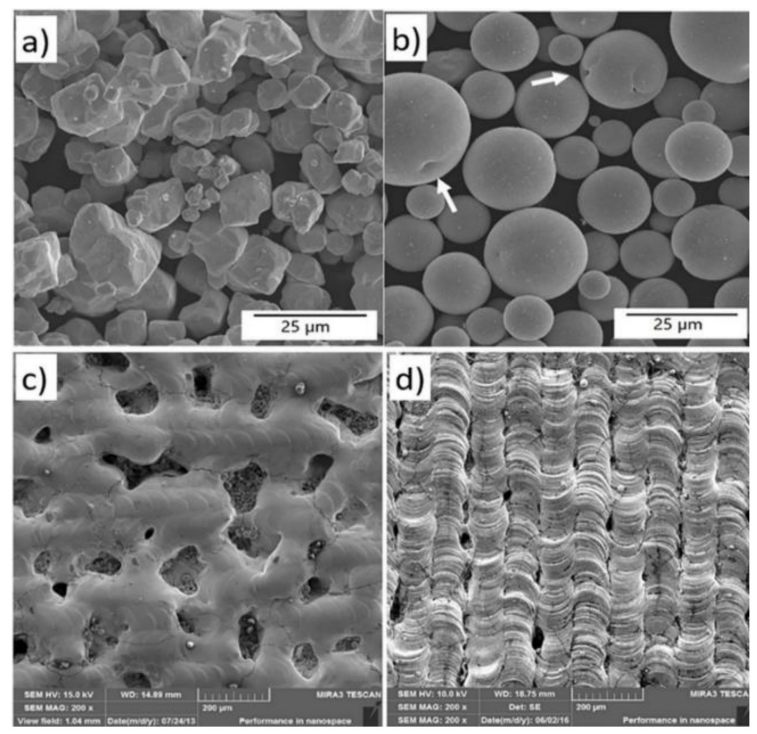

Figure 4. (SEM) images comparing surface morphology of tungsten coupons under similar process conditions. Coupon (c) was produced using the feedstock (a), while coupon (d) was produced using feedstock (b) [34].

Wang et al. [31] have noticed a more than $14 \%$ increase in laser energy absorptivity after spheroidization of irregular tungsten powder (Figure 5). Zhang et al. [30] have also found that tungsten powder particle size is inversely correlated with powder energy absorption. They conducted numerical simulations by which they predicted that particles with smaller size are likely to experience a more uniform distribution of laser energy (Figure 6). The effect of particle size on melt track continuity was also reported in the same study (Figure 7). The smaller particle feed stock experienced full melting and continuous melt track as a result of sufficient energy absorption, while at the same laser conditions, larger particles showed balling and lack of fusion to the substrate surface.

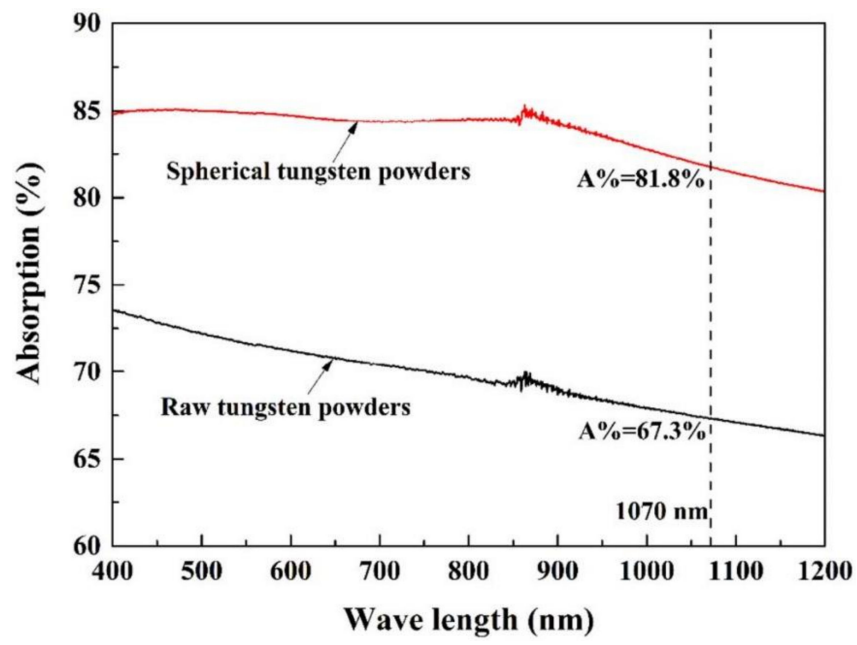

Figure 5. Laser energy absorption of spherical W powder vs. irregular W powder [31]. 


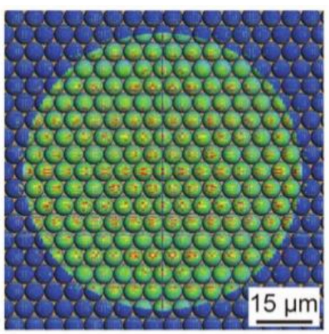

(a)

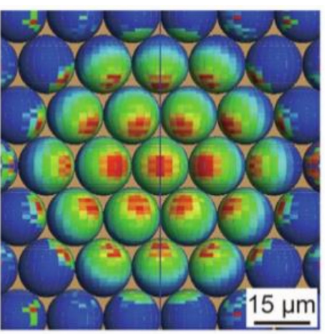

(b)

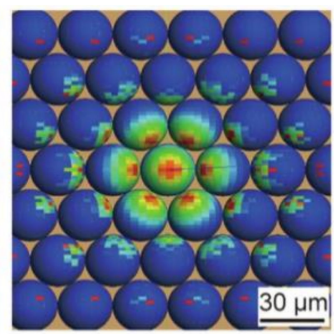

(c)

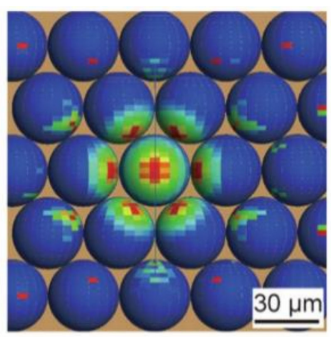

(d)

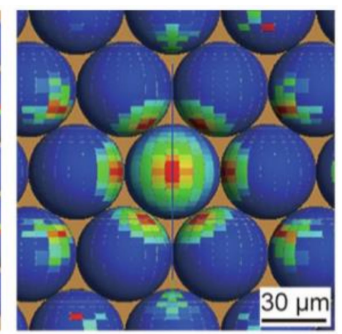

(e)

Figure 6. Laser energy absorption for different powder sizes (a) $5 \mu \mathrm{m}$, (b) $15 \mu \mathrm{m}$, (c) $25 \mu \mathrm{m}$, (d) $35 \mu \mathrm{m}$, (e) $45 \mu \mathrm{m}[30]$.

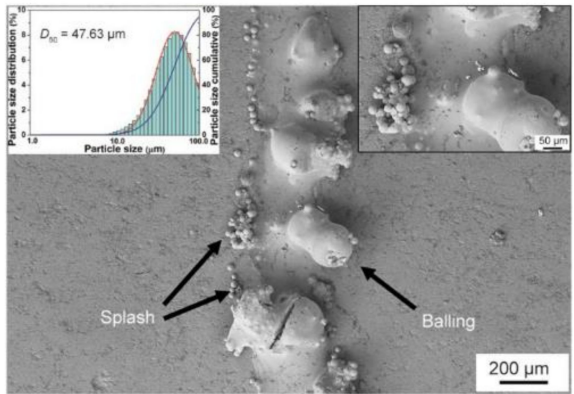

(a)

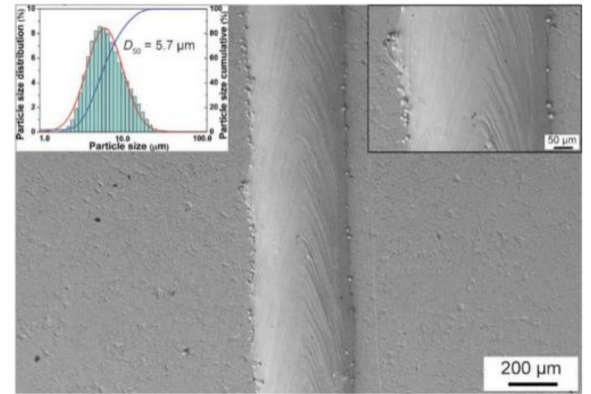

(b)

Figure 7. Single melt-track continuity using tungsten feedstock with different particle size, process conditions are identical for both tracks, (a) D50 $=47.63 \mu \mathrm{m}$, (b) D50 $=5.7 \mu \mathrm{m}$ [30].

Although small sized particles are favored in terms of packing density and energy absorption, the use of very fine powders is likely detrimental to producing bulk tungsten parts by LPBF. Agglomeration tendency is increased at smaller particle sizes and is much noticeable in sub-micron sized particles as a result of Van Der Waals attractive forces and reduced powder flowability $[28,30,46]$. Fine powders are also more susceptible to oxidation and humidity as a result of the increased surface area [32]. Table 1 presents the feedstock (spherical) size distribution reported in literature for theoretical densities $97 \%$ and above. The recommended feedstock size and morphology for LPBF of unalloyed tungsten is spherical powder with size distribution between $5 \mu \mathrm{m}$ and $25 \mu \mathrm{m}$.

\subsubsection{Substrate}

The substrate material compatibility with the selected feedstock material is a main contributor to successful LPBF operations. A sufficient bond between the first layers and the underlaying substrate is essential to keeping components in place until process completion. In analogy to metal fusion welding, compatibility is typically existent between the powder metal and a substrate of the same kind [50-52]. The selective laser melting and subsequent solidification of unalloyed tungsten on unalloyed tungsten substrate encourages a homologous wetting condition, in which nucleation energy barriers are typically diminished. The result is immediate and seamless grain growth across the solidliquid interface $[40,49]$. 
Table 1. Feedstock size distribution and substrate material type used for LPBF of high-density tungsten (W).

\begin{tabular}{|c|c|c|c|}
\hline Relative Density & Powder Size Distribution $(\mu \mathrm{m})$ & Substrate Material & Ref. \\
\hline $98.71 \%$ & $\begin{array}{l}\mathrm{D} 10=9.04 \\
\mathrm{D} 50=14.8 \\
\mathrm{D} 90=23.7\end{array}$ & - & [37] \\
\hline $98.7 \%$ & $\begin{array}{l}\mathrm{D} 10=17.7 \\
\mathrm{D} 50=27.4 \\
\mathrm{D} 90=41.8\end{array}$ & - & [36] \\
\hline $98.7 \%$ & $15-53$ & Tungsten & [44] \\
\hline $98.51 \%$ & $5-25$ & 316L stainless steel & [38] \\
\hline $98.50 \%$ & $\begin{array}{l}\text { D10 }=10.47 \\
\text { D50 }=16.24 \\
\text { D90 }=23.67\end{array}$ & - & [39] \\
\hline $98.5 \%$ & $15-45$ & Tungsten & [40] \\
\hline $98.4 \%$ & $\begin{array}{l}\mathrm{D} 10=10.4 \\
\mathrm{D} 50=15.8 \\
\mathrm{D} 90=23.8\end{array}$ & - & {$[41]$} \\
\hline $98.4 \%$ & $\begin{array}{c}\text { D10 }=8.25 \\
\text { D50 }=14.41 \\
\text { D90 }=24.25\end{array}$ & Stainless steel & [43] \\
\hline $98.31 \%$ & $\begin{array}{c}\text { D10 = } 10 \\
\text { D50 = } 15.87 \\
\text { D90 = } 24.86\end{array}$ & 316L stainless steel & [42] \\
\hline $97.3 \%$ & $\begin{array}{c}\text { D10 }=8.5 \\
\text { D50 }=31.1 \\
\text { D90 }=41.31\end{array}$ & Tungsten & [35] \\
\hline $97.5 \%$ & $\begin{array}{l}\text { D10 }=10.3 \\
\text { D50 }=16.6 \\
\text { D90 }=28.2\end{array}$ & - & [47] \\
\hline $97 \%$ & $42-52$ & Titanium & [48] \\
\hline $97 \%$ & $\begin{array}{l}\mathrm{D} 10=9.04 \\
\mathrm{D} 50=14.8 \\
\mathrm{D} 90=23.7\end{array}$ & Tungsten & [49] \\
\hline
\end{tabular}

A number of publications have also reported successful LPBF of tungsten (W) on compositionally different substrates such as steel [33,38,42,53,54] and titanium [48]. The presence of compositional difference between the liquid and solid phases in such cases is expected to impose a nucleation energy barrier and hinder the spread of molten metal on the substrate, leading to insufficient wetting. This problem could be redeemed to some extent in LPBF of tungsten (W) using a substrate material with matching crystal structure such as steel (bcc crystal structure), given that a clean and oxide free surface is maintained during the process $[29,30]$. An ongoing study by the present authors (Figure 8 ) confirms the published reports on successful printing of unalloyed tungsten on steel. 


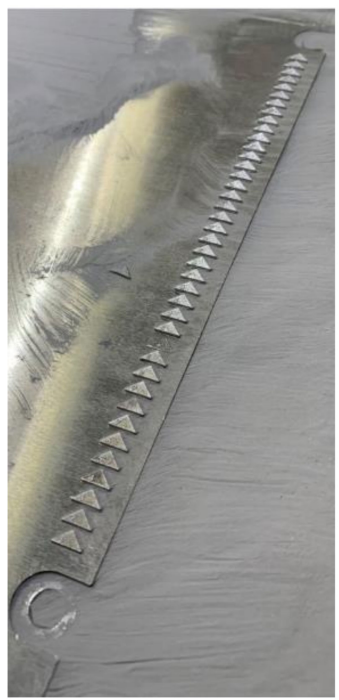

(a)

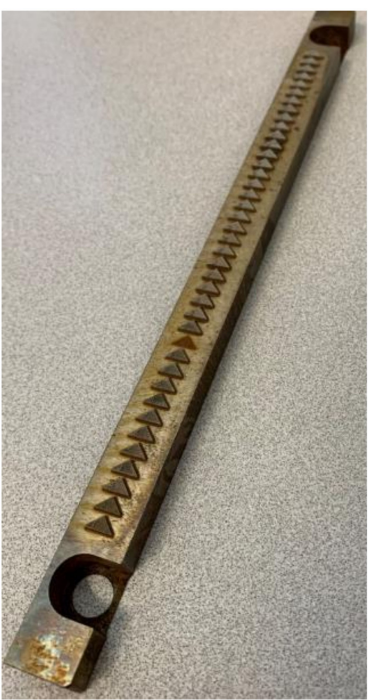

(b)

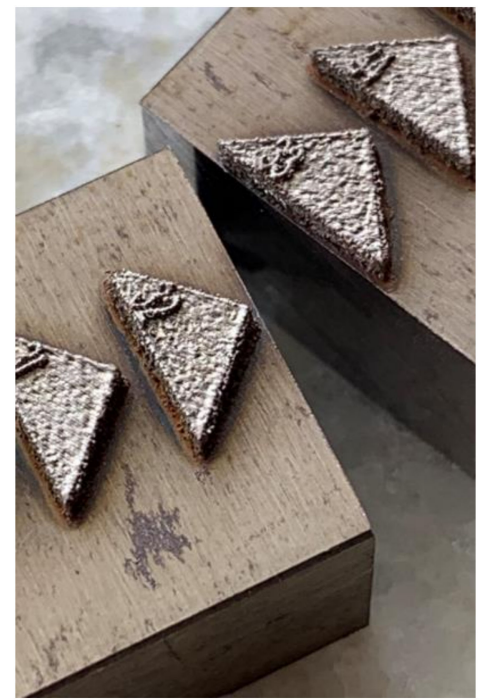

(c)

Figure 8. Tungsten (W) successsfuly printed via LPBF on carbon steel substrate (ongoing study by the present authors); (a) tungsten samples as appeared inside the LBPF build chamber; (b) part of the substrate cut by EDM with the samples on top; and (c) closeup of the printed samples on the steel substrate.

\subsection{Process Maps}

\subsubsection{Single Track}

Melt track continuity has direct influence on layer quality as well as part density [55-58]. Process optimization for single track continuity in LPBF of unalloyed tungsten is also important for anti-scatter grids applications that involve thin-walled features $(<100 \mu \mathrm{m})[31,40,59]$. The continuity of a single melt track is influenced by the melt pool geometry, which is influenced by the ratio of laser power to scanning speed $p / v[38,59-63]$.

Xie et al. [59] studied the effect of laser power and scanning speed on single melt track continuity (melted powder on solid layer) and defined a continuous melt track zone between $(0.4$ and $6 \mathrm{~J} / \mathrm{mm})$. The optimum window for production of thin-walled features was however narrowed to $(0.6-1.3 \mathrm{~J} / \mathrm{mm})$. Ren et al. [38] also studied the effect of laser power and scanning speed on tungsten melt track continuity (melted powder on powder bed) and defined an optimal process map (Figure 9a) for continuous and uniform melt tracks. Based on both studies, a common $p / v$ ratio of $(0.6-1.5 \mathrm{~J} / \mathrm{mm})$ may be expected to produce continuous melt tracks.

Another study by Vrancken et al. [60] on the influence of laser power and scanning speed on crack initiation was done on the substrate surface under LPBF conditions (no powder). They noticed a higher cracking tendency at power levels above $380 \mathrm{~W}$ (Figure 9b) and defined a $p / v$ limit below $3.5 \mathrm{~J} / \mathrm{mm}$ for macrocrack-free tracks. Microcracks however were still present at lower $p / v$ ratios covering a 300-400 $\mu \mathrm{m}$ zone around the melt track.

\subsubsection{Process Maps for Bulk Objects}

Li et al. [42] investigated the influence of process parameters such as laser power $P$, scanning speed $v$, and hatch spacing $h$ on the density of as-LPBF bulk tungsten (W) parts and achieved maximum relative density of $98.31 \%$. Densities were calculated using the Archimedes method and process maps were produced in the study (Figure 10). They found a direct correlation between the applied laser power and the resulting density as shown in Figure 10a. The influence of hatch spacing and scanning speed was however insignificant as reported by the study (Figure 10b,c). Densities above $98 \%$ were obtained at powers in the range of 250-300 W with hatch distance between 0.08 and $0.1 \mathrm{~mm}$ and layer thickness of $0.03 \mathrm{~mm}$. 


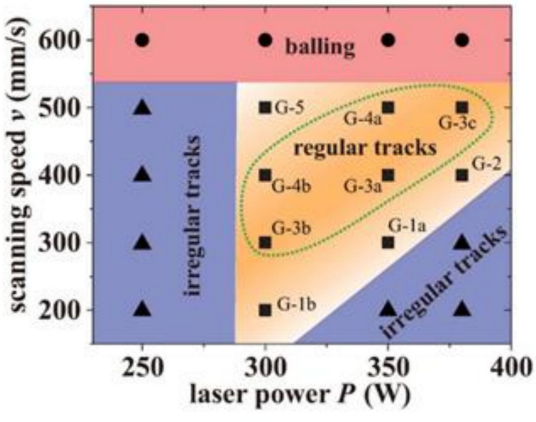

(a)

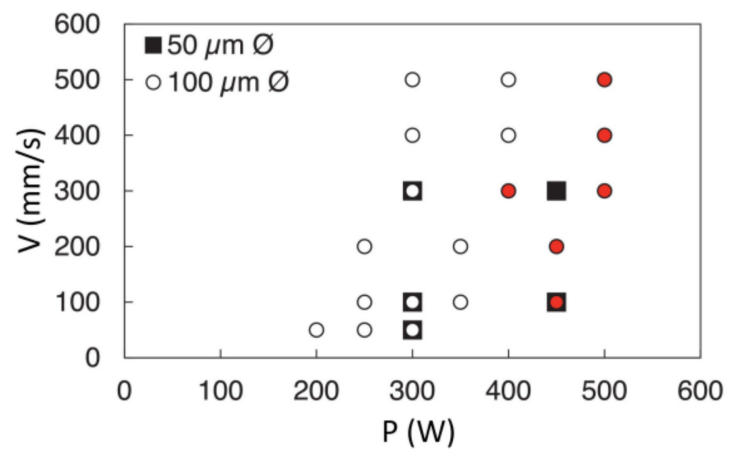

(b)

Figure 9. (a) Process map for continuous W melt tracks (continuous zone is shaded with yellow) [38] (b) process map for crack-free W melt tracks (lasers with two different beam diameters were used in the study $(50 \mu \mathrm{m}, 100 \mu \mathrm{m})$ and cracking conditions are marked in red) [60].

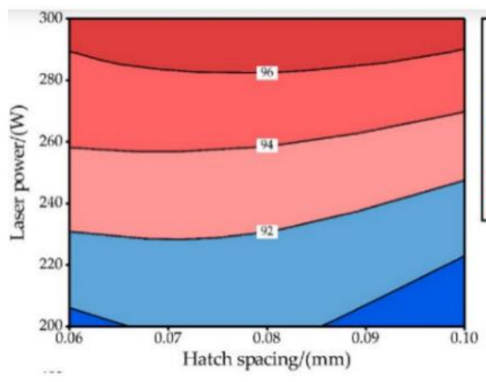

(a)
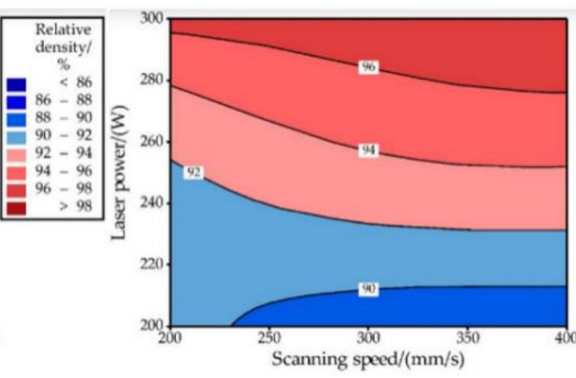

(b)
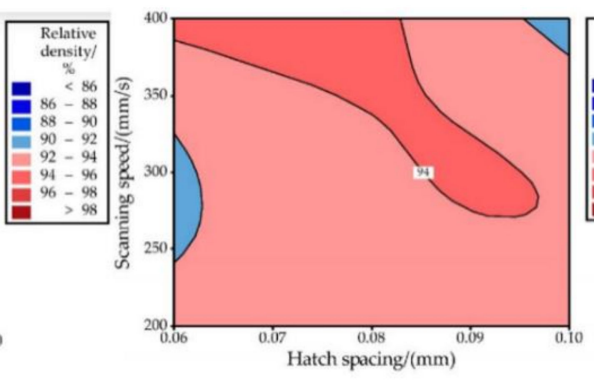

(c)

Figure 10. Process maps for tungsten (W); (a) laser power vs. hatch spacing; (b) laser power vs. scanning speed; and (c) scanning speed vs. hatch spacing, [42].

Xiong et al. [41] have also conducted density measurements via image analysis and formulated process windows for the scanning speeds and laser powers required for highdensity tungsten $(\mathrm{W})$. They produced coupons with densities $97.3-98.1 \%$ at powers between 250 and $300 \mathrm{~W}$ and scanning speeds between 400 and $500 \mathrm{~mm} / \mathrm{s}$. It should be noted that density measurements by the image processing technique were found slightly higher as compared to Archimedes method when both methods were applied to the same samples (Figure 11a,b) [37,39]. The difference in density measurements between the two methods was attributed to the effect of open pores according to [39]. Another plausible reason behind the higher density measurements by image analysis is the possibility that some of the pores are filled with metal debris during cutting/polishing prior to image analysis, unlike the case when measuring density by the Archimedes method.

The effect of open pores being infiltrated by water during density measurements by Archimedes method was utilized by Huang et al. [54] to obtain the percentage of open pores in tungsten specimens produced by LPBF. They measured the density by Archimedes method for the same samples before and after boiling in deionized water for three hours. They found that the percentage of open (apparent) porosity is higher as compared to closed porosity in unalloyed tungsten made by LPBF when using pulsed laser mode (Figure 12). They also found that increasing the hatch distance and laser point distance (equivalent to increasing the scanning speed) increased the lack of fusion (open) porosity. On the other hand, using smaller hatch distances and laser point distances promoted keyhole (closed) porosity. 


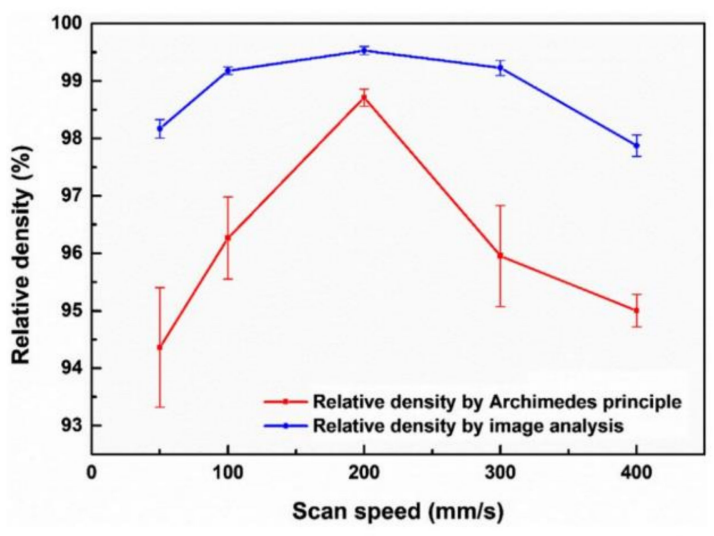

(a)

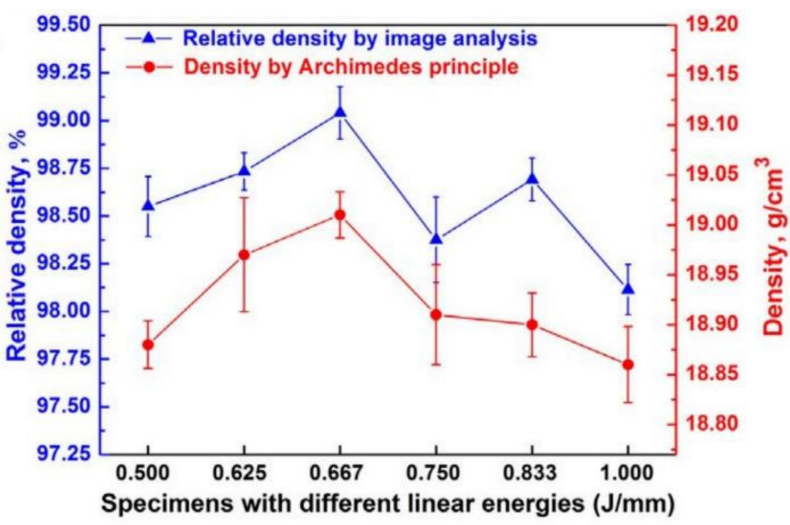

(b)

Figure 11. Comparison between density values for tungsten (W) after LPBF as obtained by Archimedes method and image analysis (a) [37], (b) [39].

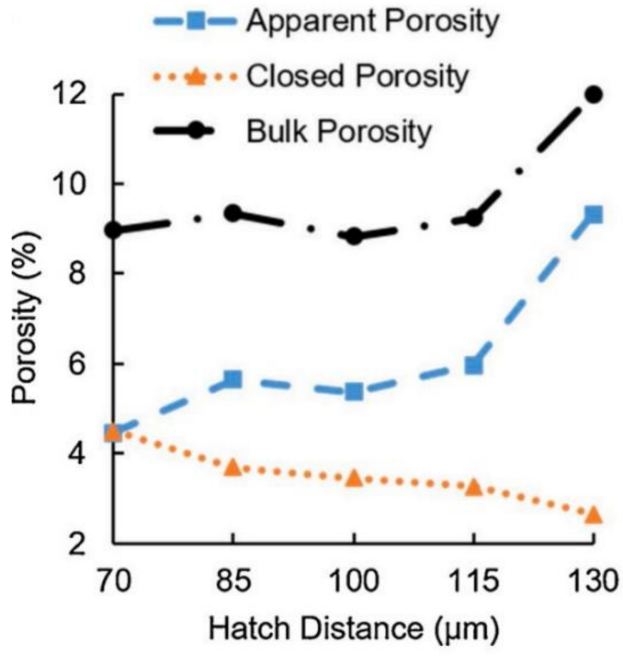

(a)

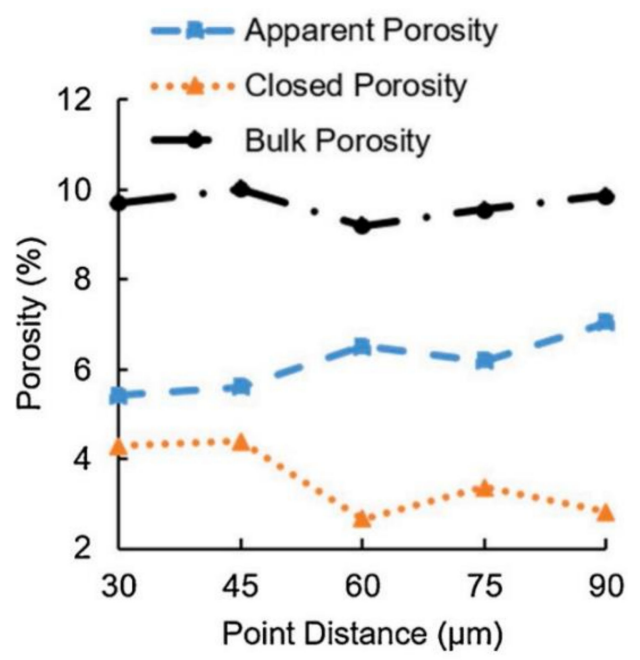

(b)

Figure 12. Effect of (a) hatch distance and (b) point distance, on porosity percentage in bulk tungsten (W) samples [54].

A number of studies have investigated the resulting density at different levels of volumetric energy density $\left(E_{v}\right)$, a quantity that represents the collective effect of laser power $(P)$, scanning speed $(v)$, hatch spacing $(h)$, and layer thickness $(t)$, as follows $[38,40,43]$ :

$$
E_{v}=\frac{P}{v h t}
$$

Some discrepancies however are present in the reported $E_{v}$ values for high-density tungsten (W). Guo et al. [43] reported an optimum $E_{v}$ around $1000 \mathrm{~J} / \mathrm{mm}^{3}$, by which they produced unalloyed tungsten coupons with relative density of $98.4 \%$. The process windows for high densities were defined in the study at laser powers in the range of 200-350 W, scanning speeds between $200 \mathrm{~mm} / \mathrm{s}$ and $400 \mathrm{~mm} / \mathrm{s}$, layer thickness of $20 \mu \mathrm{m}$, and hatch spacing of $50 \mu \mathrm{m}$. Others have defined a much lower optimum window using $30 \mu \mathrm{m}$ layer thickness $\left(E_{v}=214-350 \mathrm{~J} / \mathrm{mm}^{3}\right.$ for $>98 \%$ of theoretical density). The reported ranges for laser powers, scanning speeds, and hatch distance were 150-300 W, 200-400 mm/s, and $80-100 \mu \mathrm{m}$ respectively. Table 2 shows the process parameters at which densities of $97 \%$ and above were achieved according to reports from literature. 
It seems that the aforementioned discrepancy in the optimum $E_{v}$ values is attributed to the differences in layer thickness in the reported studies. The change in the layer thickness from $0.03 \mathrm{~mm}$ [38] to $0.02 \mathrm{~mm}$ [43] has caused an increase in the calculated $E_{v}$ from $333 \mathrm{~J} / \mathrm{mm}^{3}$ to $1000 \mathrm{~J} / \mathrm{mm}^{3}$ and also reduced the optimum hatch distance from $0.1 \mathrm{~mm}$ to $0.05 \mathrm{~mm}$. The difference in layer thickness values between the aforementioned studies however did not show similar influence on the reported optimum laser power values.

Table 2. Process conditions for high for LPBF of high-density tungsten (W).

\begin{tabular}{|c|c|c|c|c|c|}
\hline Relative Density & $\begin{array}{c}\text { Process } \\
\text { Parameters } 1\end{array}$ & $\begin{array}{l}\text { Scanning } \\
\text { Strategy }\end{array}$ & $\begin{array}{c}\text { Build Chamber } \\
\text { Conditions }\end{array}$ & $\begin{array}{c}\text { Post Process } \\
\text { Treatment }\end{array}$ & Ref. \\
\hline $98.71 \%$ & $\begin{array}{c}P=200 \mathrm{~W} \\
v=200 \mathrm{~mm} / \mathrm{s} \\
h=0.1 \mathrm{~mm} \\
t=0.03 \mathrm{~mm} \\
E_{l}=1 \mathrm{~J} / \mathrm{mm} \\
E_{v}=333 \mathrm{~J} / \mathrm{mm}^{3}\end{array}$ & $\begin{array}{c}67^{\circ} \text { rotation } \\
\text { between layers }\end{array}$ & $\begin{array}{c}473 \text { K preheating } \\
\text { under Argon } \\
\text { shield }\end{array}$ & None & [37] \\
\hline $98.7 \%$ & $\begin{array}{c}P=360 \mathrm{~W} \\
v=600 \mathrm{~mm} / \mathrm{s} \\
h=0.08 \mathrm{~mm} \\
t=0.02 \mathrm{~mm} \\
E_{l}=0.6 \mathrm{~J} / \mathrm{mm} \\
E_{v}=375 \mathrm{~J} / \mathrm{mm}^{3}\end{array}$ & $\begin{array}{c}90^{\circ} \text { rotation } \\
\text { between layers }\end{array}$ & $\begin{array}{c}353 \text { K preheating } \\
\text { under Argon } \\
\text { shield }\end{array}$ & & [36] \\
\hline $98.7 \%$ & $\begin{array}{c}P=150 \mathrm{~W} \\
v=350 \mathrm{~mm} / \mathrm{s} \\
h=0.08 \mathrm{~mm} \\
t=0.025 \mathrm{~mm} \\
E_{l}=0.43 \mathrm{~J} / \mathrm{mm}^{3} \\
E_{v}=214 \mathrm{~J} / \mathrm{mm}^{3}\end{array}$ & $\begin{array}{c}67^{\circ} \text { rotation } \\
\text { between layers }\end{array}$ & $\begin{array}{c}- \\
\text { Argon shield }\end{array}$ & None & [44] \\
\hline $98.51 \%$ & $\begin{array}{c}P=300 \mathrm{~W} \\
v=300 \mathrm{~mm} / \mathrm{s} \\
h=0.1 \mathrm{~mm} \\
t=0.03 \mathrm{~mm} \\
E_{l}=1 \mathrm{~J} / \mathrm{mm} \\
E_{v}=333 \mathrm{~J} / \mathrm{mm}^{3}\end{array}$ & $\begin{array}{c}67^{\circ} \text { rotation } \\
\text { between layers }\end{array}$ & $\begin{array}{c}473 \mathrm{~K} \text { preheating } \\
\text { under Argon } \\
\text { shield }\end{array}$ & $\begin{array}{c}2 \mathrm{~h} \\
\text { annealing in } \\
\text { vacuum at 1100C }\end{array}$ & [38] \\
\hline $98.50 \%$ & $\begin{array}{c}P=200-400 \mathrm{~W} \\
v=200-300 \mathrm{~mm} / \mathrm{s} \\
h=- \\
t=0.02 \mathrm{~mm} \\
E_{l}=- \\
E_{v}=-\end{array}$ & $\begin{array}{c}67^{\circ} \text { rotation } \\
\text { between layers }\end{array}$ & $\begin{array}{c}323 \text { K preheating } \\
\text { under Argon } \\
\text { shield }\end{array}$ & None & [39] \\
\hline $98.5 \%$ & $\begin{array}{c}P=400 \mathrm{~W} \\
v=454 \mathrm{~mm} / \mathrm{s} \\
\text { (calculated) } \\
h=0.08 \mathrm{~mm} \\
t=0.04 \mathrm{~mm} \\
E_{l}=0.88 \mathrm{~J} / \mathrm{mm} \\
(\text { calculated) } \\
E_{v}=275 \mathrm{~J} / \mathrm{mm}^{3}\end{array}$ & $\begin{array}{c}90^{\circ} \text { rotation } \\
\text { between layers }\end{array}$ & $\begin{array}{c}1273 \text { K preheating } \\
\text { under Argon } \\
\text { shield }\end{array}$ & None & [40] \\
\hline $98.4 \%$ & $\begin{array}{c}P=300 \mathrm{~W} \\
v=400 \mathrm{~mm} / \mathrm{s} \\
h=- \\
t=0.02 \mathrm{~mm} \\
E_{l}=0.75 \mathrm{~J} / \mathrm{mm} \\
E_{v}=-\end{array}$ & $\begin{array}{c}67^{\circ} \text { rotation with } \\
\text { double } \\
\text { remeltingbetween } \\
\text { layers }\end{array}$ & $\begin{array}{c}453 \mathrm{~K} \text { preheating } \\
\text { under Argon } \\
\text { shield }\end{array}$ & None & [41] \\
\hline
\end{tabular}


Table 2. Cont.

\begin{tabular}{|c|c|c|c|c|c|}
\hline Relative Density & $\begin{array}{c}\text { Process } \\
\text { Parameters } 1\end{array}$ & $\begin{array}{l}\text { Scanning } \\
\text { Strategy }\end{array}$ & $\begin{array}{c}\text { Build Chamber } \\
\text { Conditions }\end{array}$ & $\begin{array}{c}\text { Post Process } \\
\text { Treatment }\end{array}$ & Ref. \\
\hline $98.4 \%$ & $\begin{array}{c}P=300 \mathrm{~W} \\
v=300 \mathrm{~mm} / \mathrm{s} \\
h=0.05 \mathrm{~mm} \\
t=0.02 \mathrm{~mm} \\
E_{l}=1 \mathrm{~J} / \mathrm{mm} \\
E_{v}=1000 \mathrm{~J} / \mathrm{mm}^{3}\end{array}$ & $\begin{array}{c}67^{\circ} \text { rotation } \\
\text { between layers }\end{array}$ & $\begin{array}{c}473 \mathrm{~K} \text { preheating } \\
\text { under Argon } \\
\text { shield }\end{array}$ & None & [43] \\
\hline $98.31 \%$ & $\begin{array}{c}P=300 \mathrm{~W} \\
v=400 \mathrm{~mm} / \mathrm{s} \\
h=0.08 \mathrm{~mm} \\
t=0.03 \mathrm{~mm} \\
E_{l}=0.75 \mathrm{~J} / \mathrm{mm} \\
E_{v}=312 \mathrm{~J} / \mathrm{mm}^{3}\end{array}$ & $\begin{array}{c}67^{\circ} \text { rotation } \\
\text { between layers }\end{array}$ & $\begin{array}{c}423 \mathrm{~K} \text { preheating } \\
\text { under Argon } \\
\text { shield }\end{array}$ & None & {$[42]$} \\
\hline $98.1 \%$ & $\begin{array}{c}P=300 \mathrm{~W} \\
v=400 \mathrm{~mm} / \mathrm{s} \\
h=- \\
t=0.02 \mathrm{~mm} \\
E_{l}=0.75 \mathrm{~J} / \mathrm{mm} \\
E_{v}=-\end{array}$ & $\begin{array}{c}67^{\circ} \text { rotation } \\
\text { between layers }\end{array}$ & $\begin{array}{c}453 \mathrm{~K} \text { preheating } \\
\text { under Argon } \\
\text { shield }\end{array}$ & None & {$[41]$} \\
\hline $97.5 \%$ & $\begin{array}{c}P=400 \mathrm{~W} \\
v=600 \mathrm{~mm} / \mathrm{s} \\
h=0.1 \mathrm{~mm} \\
t=0.03 \mathrm{~mm} \\
E_{l}=0.67 \mathrm{~J} / \mathrm{mm} \\
E_{v}=222 \mathrm{~J} / \mathrm{mm}^{3}\end{array}$ & $\begin{array}{c}67^{\circ} \text { rotation } \\
\text { with } h / 3 \\
\text { offset between } \\
\text { layers }\end{array}$ & $\begin{array}{c}1273 \text { K preheating } \\
\text { under Argon } \\
\text { shield }\end{array}$ & None & [47] \\
\hline $97.3 \%$ & $\begin{array}{c}P=300 \mathrm{~W} \\
v=750 \mathrm{~mm} / \mathrm{s} \\
h=0.06 \mathrm{~mm} \\
t=0.03 \mathrm{~mm} \\
E_{l}=0.4 \mathrm{~J} / \mathrm{mm} \\
E_{v}=222 \mathrm{~J} / \mathrm{mm}^{3} \\
P=200 \mathrm{~W} \\
v=100 \mathrm{~mm} / \mathrm{s} \\
h=0.115 \mathrm{~mm} \\
t=0.05 \mathrm{~mm} \\
E_{l}=2 \mathrm{~J} / \mathrm{mm} \\
E_{v}=348 \mathrm{~J} / \mathrm{mm}^{3}\end{array}$ & $\begin{array}{c}67^{\circ} \text { rotation } \\
\text { between layers }\end{array}$ & - & None & [35] \\
\hline $97 \%$ & $\begin{array}{c}P=400 \mathrm{~W} \\
v=300 \mathrm{~mm} / \mathrm{s} \\
h=0.1 \mathrm{~mm} \\
t=0.03 \mathrm{~mm} \\
E_{l}=1.33 \mathrm{~J} / \mathrm{mm}^{3} \\
E_{v}=444 \mathrm{~J} / \mathrm{mm}^{3}\end{array}$ & $\begin{array}{c}67^{\circ} \text { rotation } \\
\text { between layers }\end{array}$ & $\stackrel{-}{\text { Argon shield }}$ & $\begin{array}{l}\text { Hot Isostatic } \\
\text { Pressing }\end{array}$ & [49] \\
\hline
\end{tabular}

${ }^{1} P$ (laser power), $v$ (scanning speed), $h$ (hatch distance), $t$ (layer thickness), $E_{l}$ (linear energy density $\left.=\frac{P}{v}\right), E_{v}$ $\left(\right.$ volumetric energy density $\left.=\frac{P}{v h t}\right)$.

\section{Structure}

\subsection{Microstructure: Grain Structure and Size Distribution}

Solidification of molten tungsten on a solid tungsten surface (substrate or previous solid layer) exhibits equiaxed epitaxial grain growth following the orientation of wetted grains at the solid-liquid interface (Figure 13a) [38]. The grain structure then follows a competitive grain growth process in the direction of maximum temperature gradient, which is typically normal to the solid/liquid front line (dashed line in Figure 13a), then bends toward the vertical direction resulting in the columnar grains shape $[29,38,52,60]$. 
The growth direction at the full product scale is also aligned with the direction of maximum temperature gradient, being also the vertical build direction as shown in Figure 13b [38].

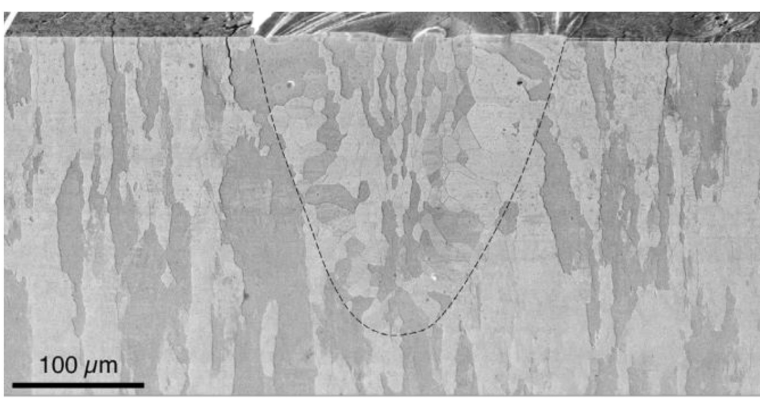

(a)

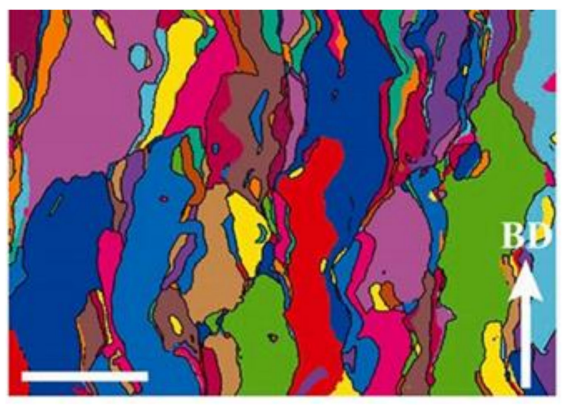

(b)

Figure 13. (a) Single $\mathrm{W}$ melt track on $\mathrm{W}$ substrate [60]; (b) grains structure along the build direction (colors are only used for elaboration) [38].

The study by Wen et al. [37] shows that the microstructure as shown in the top view (horizontal microstructure Figure 14) is influenced by the laser beam movements (scanning direction and speed). Grains grow perpendicular starting from liquid-solid interface at both sides of the melt track, Figure 14a, and gradually change direction toward the laser scanning direction (SD). As the scanning speed is increased, a more distinct feather-like pattern becomes more obvious (Figure 15). The bidirectional pattern in the microstructure shown is also indicative of the bidirectional scanning strategy that was adopted in the study (Figure 16a), and becomes much noticeable as the hatch spacing increases (Figure 16b,c) [42]. The microstructure figures also show higher cracking tendency along the melt track path when higher scanning speeds and hatch spacings are used.

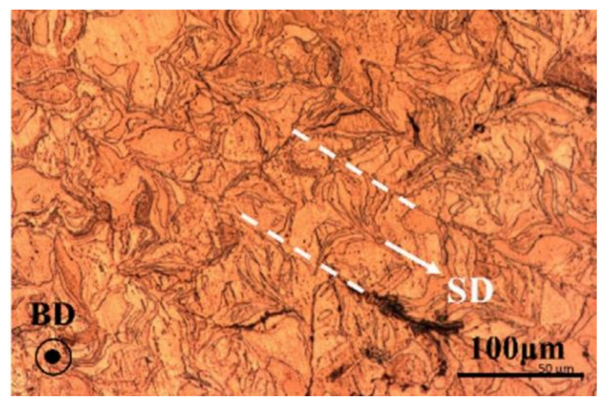

(a)

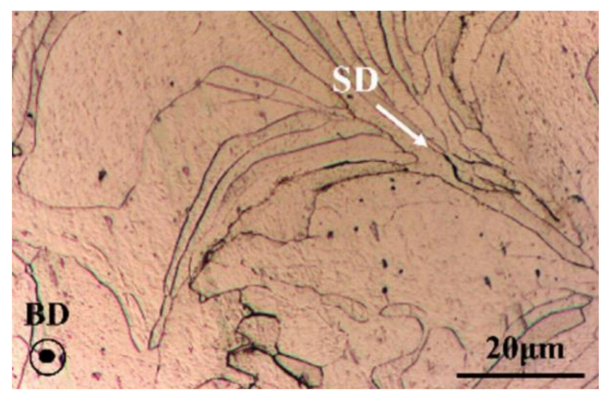

(b)

Figure 14. Horizontal microstructure of tungsten (W) produced by LPBF; notice the scanning direction influence on grains growth (a) low magnification, (b) high magnification [37].

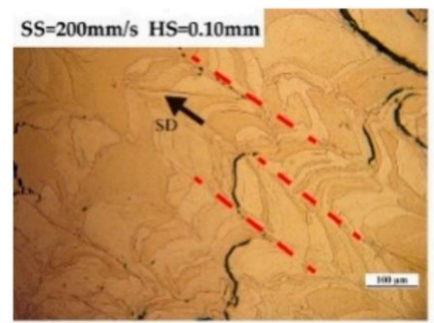

(a)

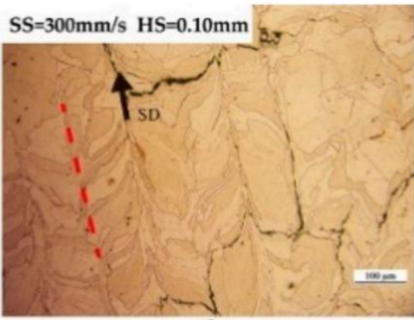

(b)

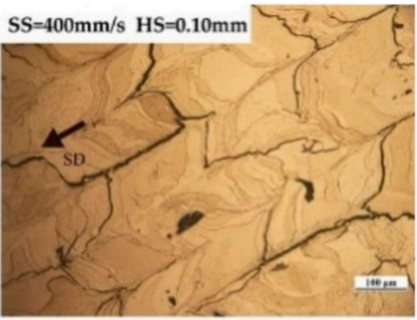

(c)

Figure 15. Change of horizontal microstructure with scanning speed variation; all other parameters were kept identical at $300 \mathrm{~W}$ laser power, $0.1 \mathrm{~mm}$ hatch spacing [42]. (a) $200 \mathrm{~mm} / \mathrm{s}$, (b) $300 \mathrm{~mm} / \mathrm{s}$, (c) $400 \mathrm{~mm} / \mathrm{s}$. 


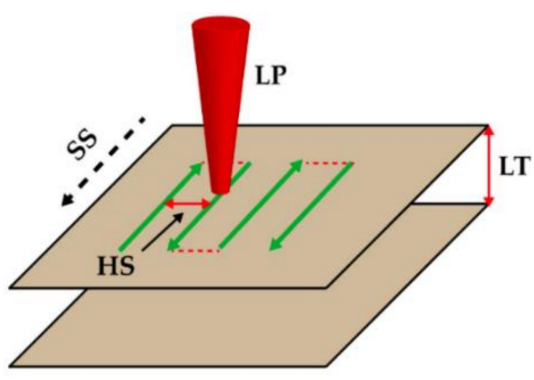

(a)

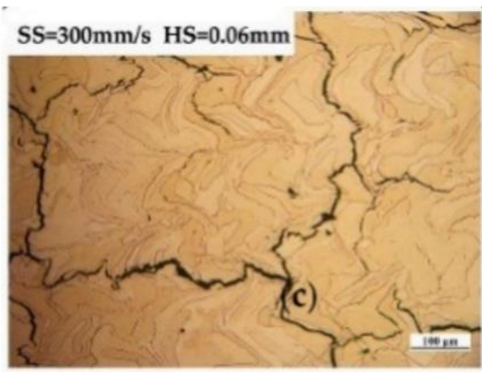

(b)

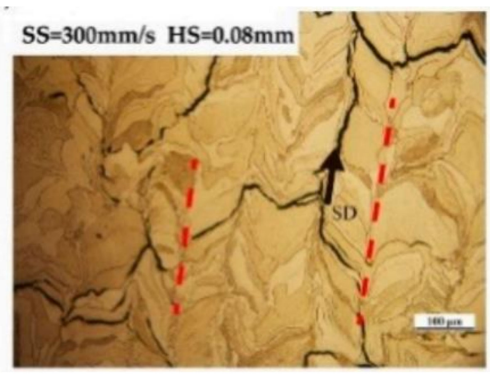

(c)

Figure 16. (a) Scanning strategy, (b) $0.06 \mathrm{~mm}$, (c) $0.8 \mathrm{~mm}$. (a) Bidirectional scanning strategy; $(b, c)$ change of grain growth pattern with hatch spacing variation, all other parameters were kept identical at $300 \mathrm{~W}$ laser power, $300 \mathrm{~mm} / \mathrm{s}$ scanning speed, [42].

The same authors also studied the effect of scanning speed on grain refinement and found consistent grains size reduction as the scanning speed increased (Figure 17) [37]. Huang et al. [54] studied the grain size distribution in unalloyed tungsten coupons made by LPBF. The measured grain size distribution has shown variation in grain sizes between the top, bottom, and side surfaces of the printed coupons. As shown in Figure 18, the bottom surface had much smaller grain size as compared to the top surface, and the sides had much larger grains than both the top and bottom surfaces. The variation in the grain sizes is an indication of the different cooling rates between the three zones, as explained by the study.

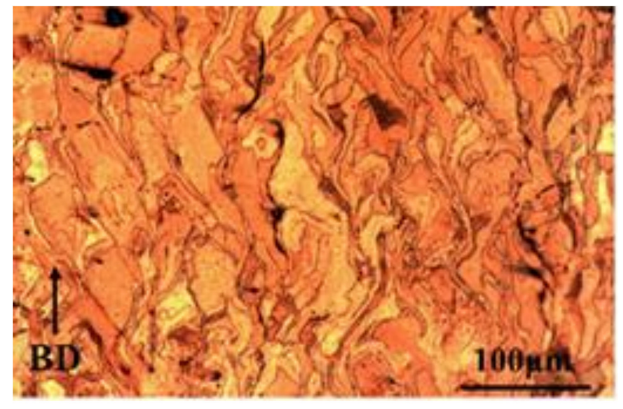

(a)

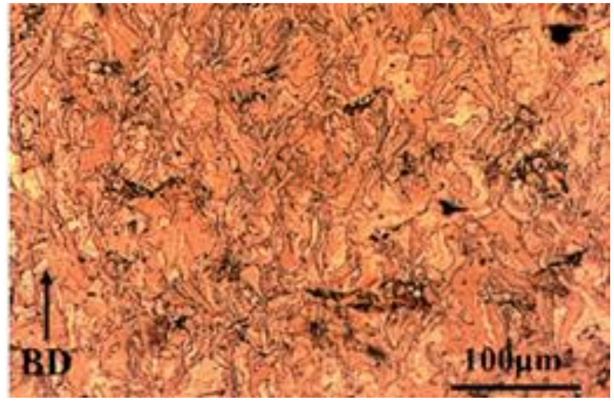

(b)

Figure 17. Effect of scanning speed on grain size in LPBF of tungsten (W). (a) $200 \mathrm{~mm} / \mathrm{s}$, (b) $400 \mathrm{~mm} / \mathrm{s}$ [37].

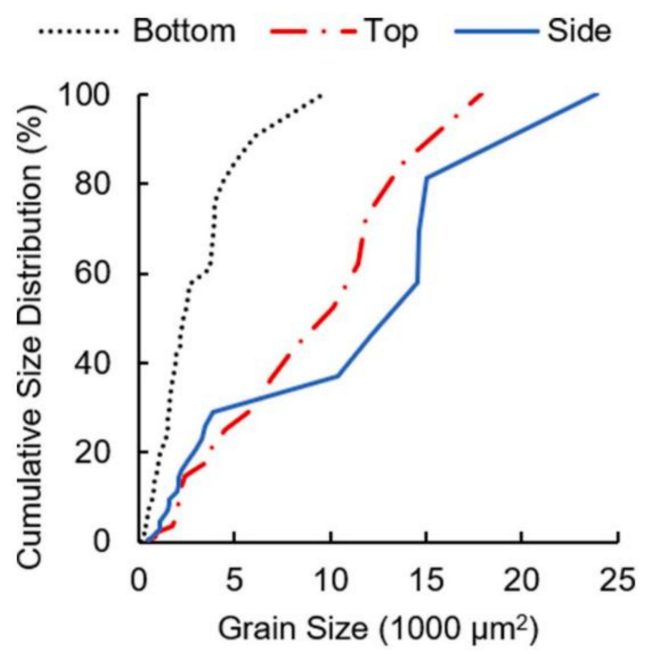

Figure 18. Grain size distribution in pure tungsten samples prepared by powder bed fusion [54]. 


\subsection{Microstructural Defects}

The mechanical properties, and hence the functionality of as-built tungsten components after LPBF are dependent on the types and population of the developed external and internal defects. The most common defects that are reported with regard to the LPBF of unalloyed tungsten are balling, porosity, and cracking.

\subsubsection{Balling and Porosity}

Zhou et al. [29] investigated the balling phenomenon in unalloyed tungsten produced by LPBF. They concluded that tungsten has high susceptibility to balling as a result of its relatively high viscosity, high thermal conductivity, high temperature-dependent surface tension, and high temperature oxygen affinity [29]. The first two features were found responsible for rapid solidification of the molten metal outer shell without allowing sufficient time for spreading of the internal unsolidified metal (Figure 19) [29,37]. The other two features were also found to promote balling by the presence of inverted thermocapillary flow (Marangoni Flow).

In ideal melt pool conditions, the metal will flow from the melt pool center (higher temperature and lower surface tension) to the outer shell (lower temperature and higher surface tension) (Figure 19a). In less ideal conditions, however, the presence of oxides at the outer shell decreases its surface tension below that of the melt pool center, thus inverting the flow from the periphery toward the melt pool center and results in a much-humped pool (Figure 19b) [29,58].

The balling effect produces a rough surface morphology as shown in Figure 19c, which obstructs the distribution of the subsequent powder layer, thus increasing the presence of porosity and entrapped unmelted powder particles. In addition to that, the presence of oxide layers at the solid surface leads to deficient bonding between the successive melt tracks and layers, which ultimately leads to internal cracking and porosity. Such an effect explains the higher oxygen concentration at porosity locations that was reported in the study (Figure 19d) [29,58].

Reduction of balling and porosity has been achieved by process parameters optimization [29,42,51]. Li et al. [42] studied the effect of laser power, scanning speed, and hatch spacing on the surface and cross-section morphology of unalloyed tungsten produced by LPBF. They have found that laser power has the most significant impact on the formation of surface defects as compared to scanning speed and hatch spacing. Figure 20a,b adopted from the study, shows that higher laser powers reduce the presence of surface defects such as pores (yellow arrow), gaps (red arrow), humps (white arrow), and cavities (black arrow). On the other hand, increasing the scanning speed and hatch distance had less significant effect as compared to the laser power (Figure 20c-f). The application of laser remelting scanning strategies has also shown a reduction in porosity and surface roughness by $0.3 \%$ and $28 \%$ respectively as reported in a study by Xiong et al. [41]. 

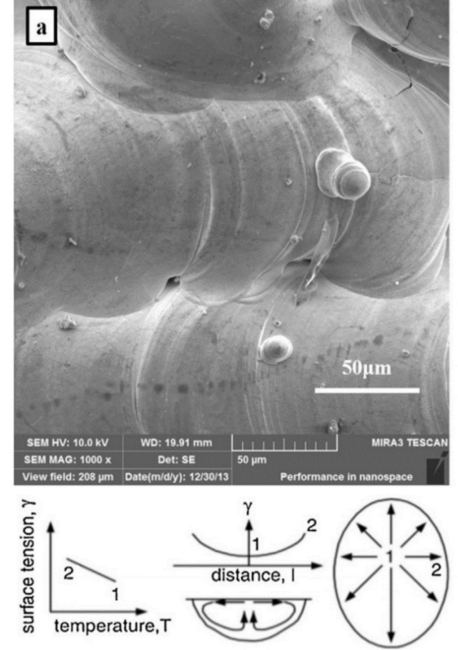

(a)
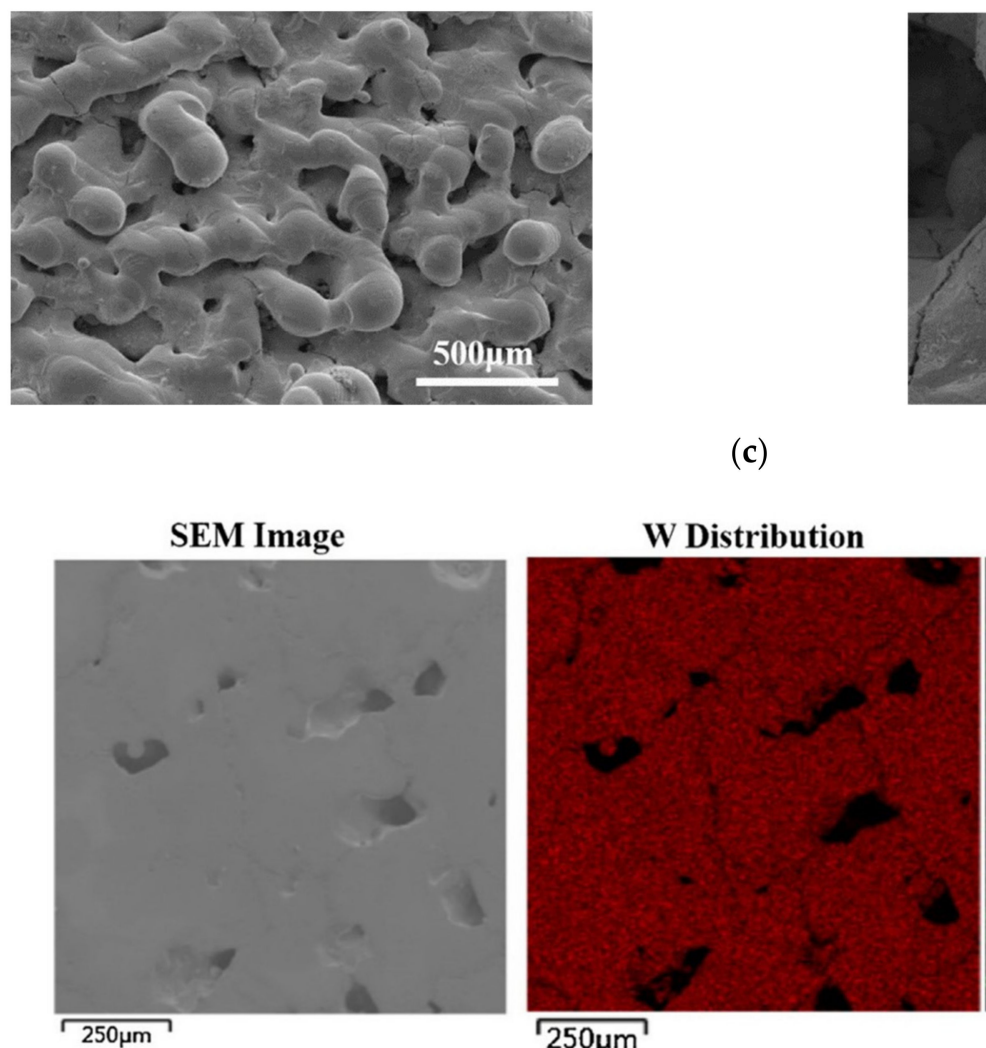

$250 \mu \mathrm{m}$

(c)

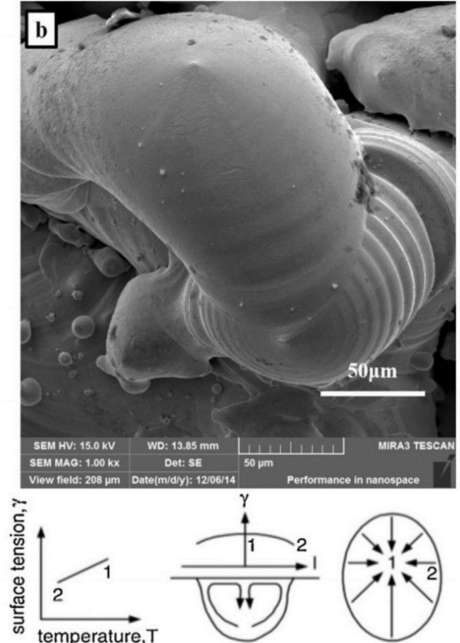

(b)
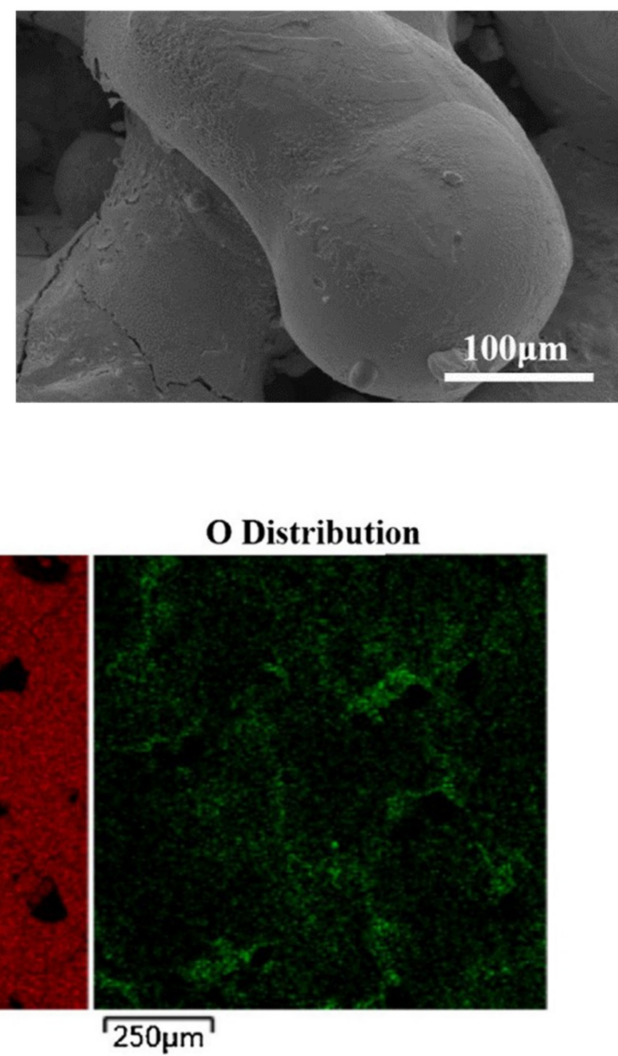

(d)

Figure 19. Effect of inverted Marangoni flow direction; (a) from center to periphery (good spreading) and (b) from periphery to center (humping/balling); (c) balling of the consolidated tungsten layer in LB-PBF process; (d) distribution of tungsten and oxygen; notice the match between high oxygen concentration zones and porosity locations [29]. 


\subsubsection{Cracking}

Tungsten possesses properties such as high melting point, high ductile-brittle transition temperature DBTT, and high notch sensitivity, present a challenge in producing crack-free tungsten parts [64]. In fact, tungsten resides at the bottom in the list of refractory metals ranked for weldability [52]. The relatively high thermal energy that is required to melt tungsten exposes the metal to a wider cooling range, resulting in significant heterogeneous thermal stresses as it cools, and eventually leads to cracks formation [52].

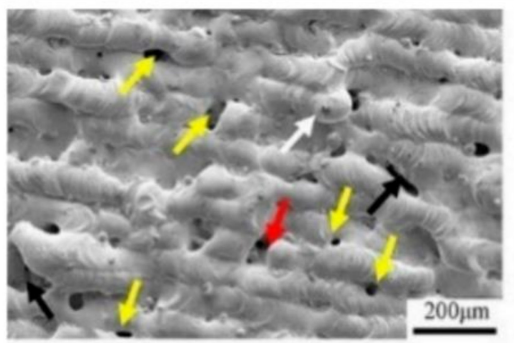

$200 \mathrm{~W}$

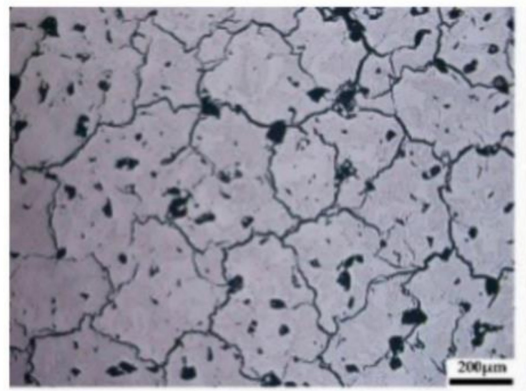

$200 \mathrm{~W}$

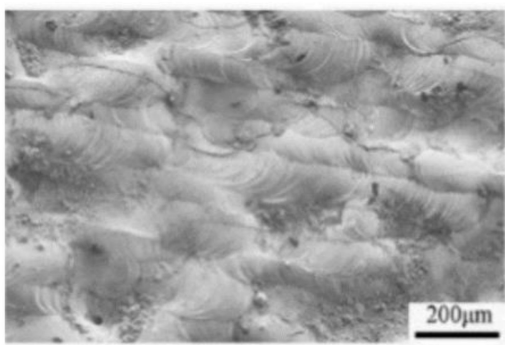

$200 \mathrm{~mm} / \mathrm{s}$

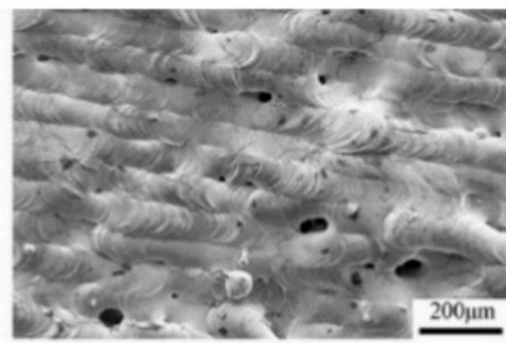

$250 \mathrm{~W}$

(a)

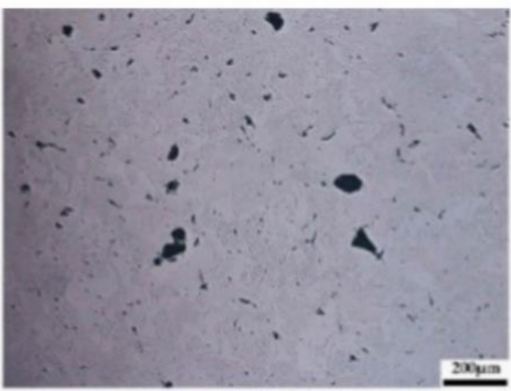

$250 \mathrm{~W}$

(b)

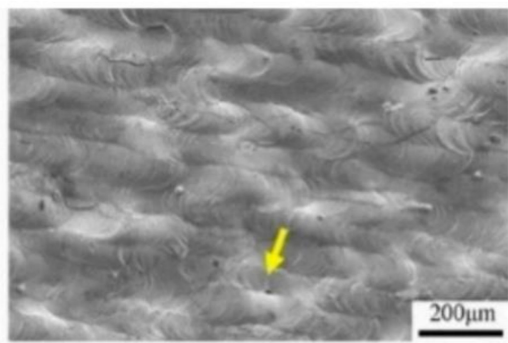

$300 \mathrm{~mm} / \mathrm{s}$

(c)

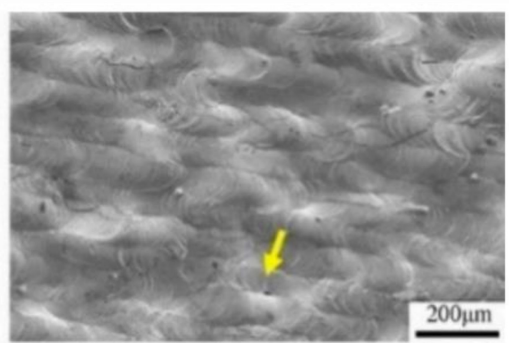

$300 \mathrm{~W}$

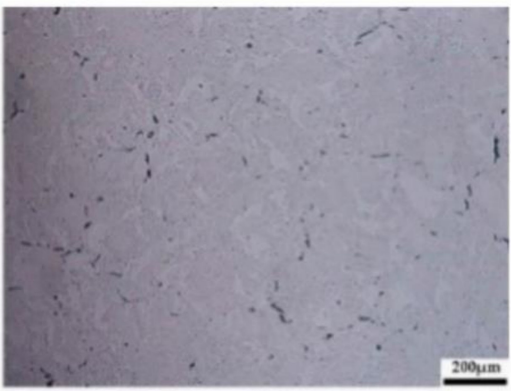

$300 \mathrm{~W}$

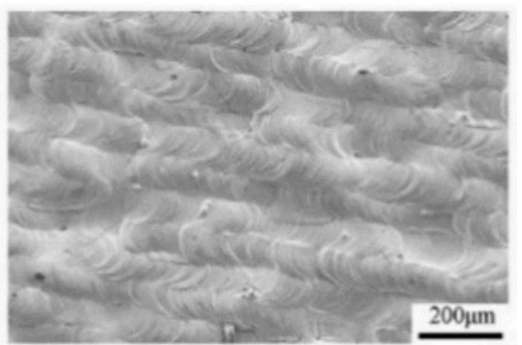

$400 \mathrm{~mm} / \mathrm{s}$

Figure 20. Cont. 


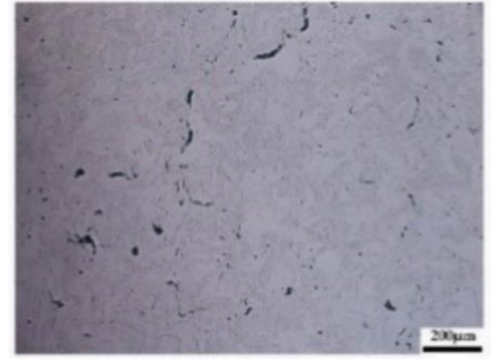

$200 \mathrm{~mm} / \mathrm{s}$

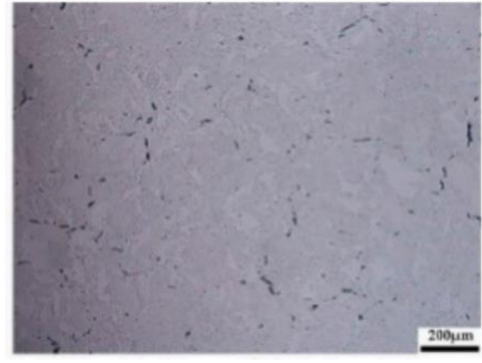

$400 \mathrm{~mm} / \mathrm{s}$

(d)

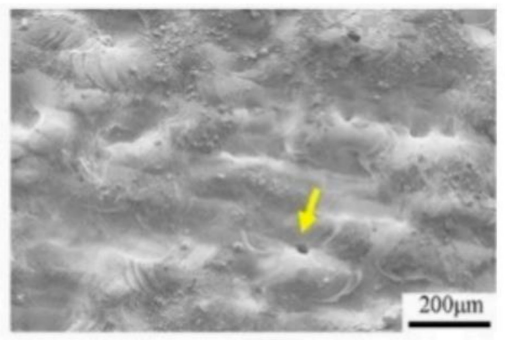

$0.06 \mathrm{~mm}$

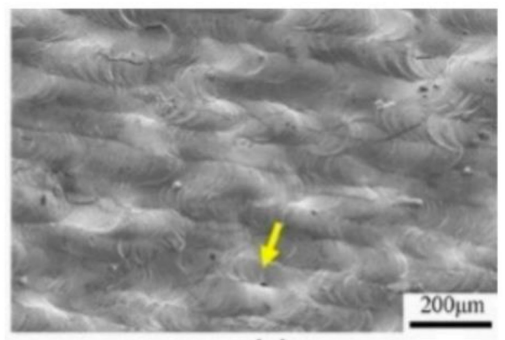

$0.08 \mathrm{~mm}$

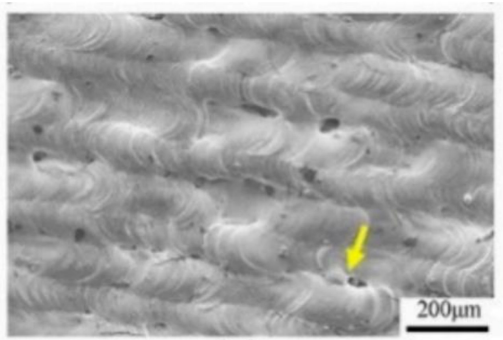

$0.1 \mathrm{~mm}$

(e)

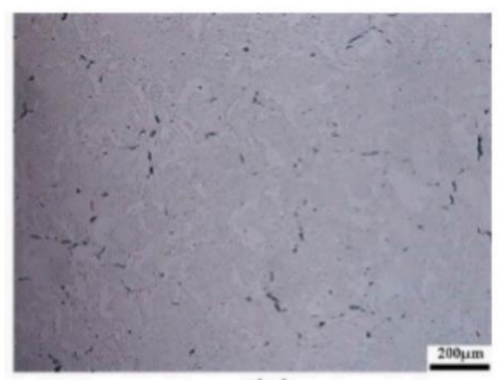

$0.08 \mathrm{~mm}$

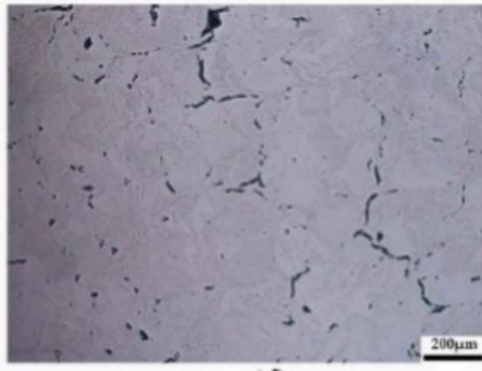

$0.1 \mathrm{~mm}$

(f)

Figure 20. (a) Effect of increasing the laser power on surface morphology (scanning speed $300 \mathrm{~mm} / \mathrm{s}$, hatch spacing $0.08 \mathrm{~mm}$ ). (b) Effect of increasing the laser power on cross-section morphology (scanning speed $400 \mathrm{~mm} / \mathrm{s}$, hatch spacing $0.08 \mathrm{~mm}$ ). (c) Effect of increasing the scanning speed on surface morphology (laser power $300 \mathrm{~W}$, hatch spacing $0.08 \mathrm{~mm}$ ). (d) Effect of increasing the scanning speed on cross section morphology (laser power $300 \mathrm{~W}$, hatch spacing $0.08 \mathrm{~mm}$ ). (e) Effect of increasing the hatch spacing on surface morphology (laser power $300 \mathrm{~W}$, scanning speed $300 \mathrm{~mm} / \mathrm{s}$ ). (f) Effect of increasing the hatch spacing on cross section morphology (laser power $300 \mathrm{~W}$, scanning speed $400 \mathrm{~mm} / \mathrm{s}$ ) [42].

The high DBTT and notch sensitivity of tungsten also promote cracking upon solidification and cooling below $673 \mathrm{~K}$ [60]. Tungsten samples that are produced by LPBF have also shown cracking at temperatures above the normal DBTT (463-673 K) as a result of oxides presence as well as other impurities such as carbon and nitrogen [65]. The underlying mechanism behind the above DBTT cracking is that such impurities interstitially precipitate in small sizes (nm) within the material lattice dislocations and restrict its mobility, leading to cracking instead of plastic relief in the stressed zones even at temperatures within the normal DBTT $[60,65]$. The higher concentration of metal oxides between the solidified grains also causes low-melt eutectic layers between the grains and promotes hot cracking [47]. The presence of such impurities is not only attributed to the shielding atmosphere during 
the printing process, but also rely on the storage conditions of the feedstock material, and the level of contamination it might have been exposed to before the LPBF process.

Wang et al. [53] investigated the crack development under different scanning strategies during LPBF of unalloyed tungsten (Figure 21). Three different scanning strategies were adopted in the study, the first employed parallel scan directions for all the layers. The second strategy involved a 67 degrees rotation of the scan lines between successive layers, and the third included laser remelting for each printed layer adopting the same 67 degrees rotation strategy. The resulting internal structure of the printed samples reveal that applying matching scan tracks between layers promotes cracking at the same locations in each layer, and results in crack growth along the build direction. On the other hand, adoption of scan track rotation between layers obstructs growth of cracks that are initiated in the previous layer and can significantly reduce cracking along the build direction. The application of remelting however is apparently not beneficial in terms of crack reduction. Such result is explained by the fact that most of the developed cracks had lengths exceeding the remelted thickness. Therefore, instead of reducing the presence of cracks, the remelting operation promoted thermal fatigue crack growth as shown in Figure $21 \mathrm{c}$ as compared to Figure 21b [53].

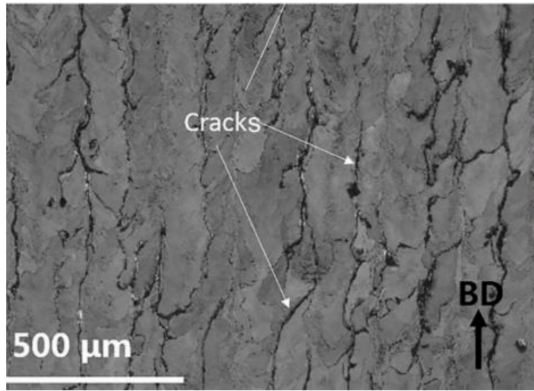

(a)

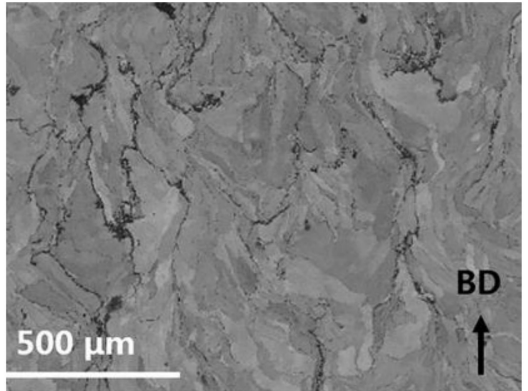

(b)

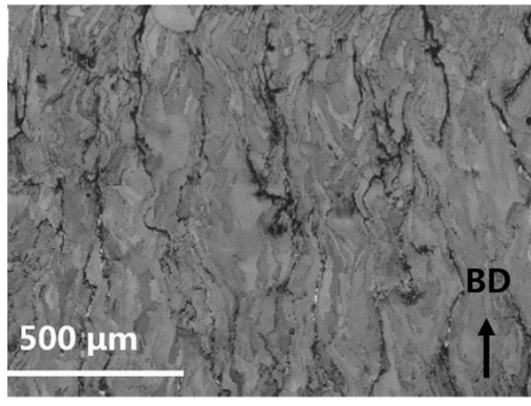

(c)

Figure 21. Influence of scanning strategy on crack development along the build direction, (a) no scan direction rotation between layers, (b) $67^{\circ}$ rotation between layers, (c) remelting applied with normal direction to melt tracks of case (b) [53].

The development of thermal stresses upon cooling of unalloyed tungsten results in cracking once they exceed its fracture strength. Wang et al. [53] reported that such condition is satisfied for a metal with $2 \mathrm{GPa}$ tensile strength if subjected to thermal gradient above $800 \mathrm{~K}$. Attempts to produce unalloyed tungsten by LPBF with substrate preheating temperature of $1273 \mathrm{~K}$ have shown noticeable reduction in cracking as reported by Müller et al. [40] and are shown in Figure 22. A complete prevention of cracking in tungsten however is expected to require substrate preheating at much higher temperatures to maintain thermal gradient below the calculated $800 \mathrm{~K}$ which is practically difficult to achieve.

Introduction of alloying elements such as tantalum, vanadium, rhenium, niobium as well as nano secondary phases such as $\mathrm{ZrC}, \mathrm{Y}_{2} \mathrm{O}_{3}, \mathrm{La}_{2} \mathrm{O}_{3}$, and $\mathrm{TiC}$ has been discussed in literature as an approach to reducing cracking in tungsten bulks [16,66-79]. The addition of such phases has been widely used in powder metallurgy as a method for grain size refinement, oxidation restraining, and dislocation mobility improvement. Attempts to add small amounts $(<6 \% \mathrm{wt})$ of tantalum and titanium as well as nano $\mathrm{ZrC}$ and $\mathrm{Y}_{2} \mathrm{O}_{3}$ have shown promising results in terms of crack suppression and grain refinement in tungsten produced by LPBF $[33,80-84]$. The underlying mechanisms by which such additions can change the produced microstructure/properties are however out of the scope of this review and have been discussed in a review by Li et al. [23]. 


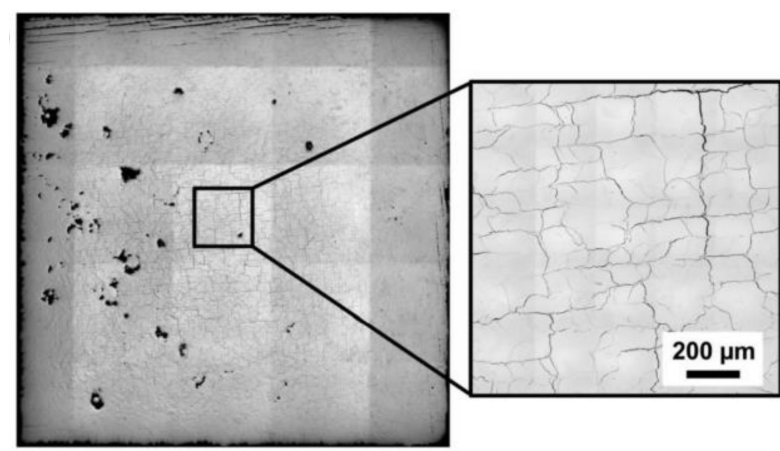

(a)

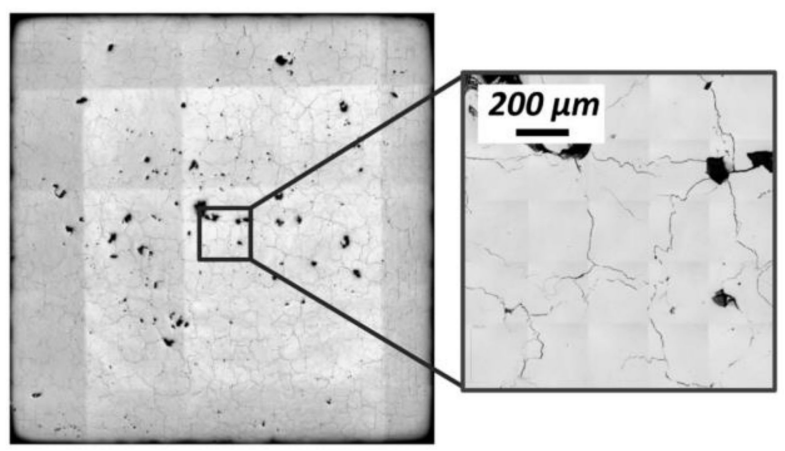

(b)

Figure 22. Effect of substrate preheating on crack development (a) $200{ }^{\circ} \mathrm{C}$, (b) $1000{ }^{\circ} \mathrm{C}[40]$.

Other attempts to reducing cracking in LPBF of unalloyed tungsten by post-process treatments have also been reported. Ren et al. [38] studied the influence of post LPBF annealing on crack reduction. Annealing after LPBF for two hours at $1100{ }^{\circ} \mathrm{C}$ in vacuum resulted in a minor growth in grain size leading to mechanical crack closure. The resulting microstructure was free of macro-crack defects with fewer micro-cracks and pores as reported in the study. Chen et al. [49] studied the effect of hot isostatic pressing (HIP) on tungsten samples after LPBF. The HIP process was carried out at $2073 \mathrm{~K}$ and $180 \mathrm{MPa}$ for four hours. The resulting microstructure after HIP revealed noticeable crack-healing effect as shown by the microstructure in Figure 23. The study also reported a minor improvement in the relative density after HIP $(0.5 \%)$.

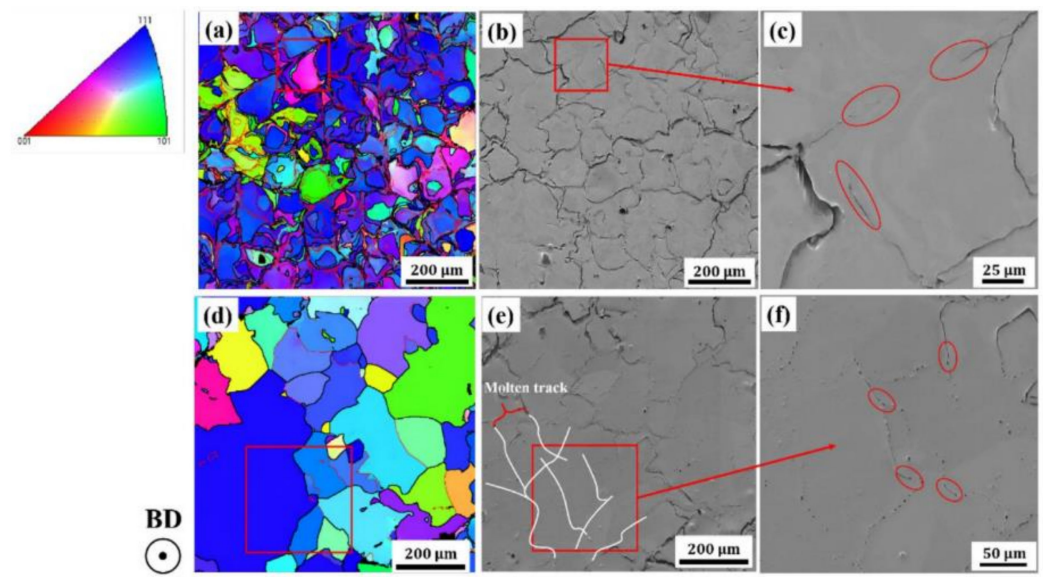

Figure 23. Crack healing effect ofter post-LPBF HIP of unalloyed tungsten. (a-c) Before HIP, (d-f) after HIP [49].

The main factors that have been found to promote balling and porosity as well as cracking during the production of tungsten by LPBF are summarized in Table 3 . The table also summarizes the expected effects that such defects will have on the produced parts and the solutions reported in literature. 
Table 3. Cause-effect-solution of the main defects that are reported in LPBF of unalloyed tungsten $(\mathrm{W})$.

\begin{tabular}{ll}
\hline Balling/Porosity & Cracking \\
\hline
\end{tabular}

Cause:

- $\quad$ Feedstock properties

Low energy absorptivity

High melt pool viscosity

High thermal conductivity

High temperature dependent surface tension

high temperature oxygen affinity

High level of impurities Cause:

High humidity

- Feedstock properties

- Process conditions

Low laser power (balling and lack of fusion porosity). $\quad$ - $\quad$ High Ductile-Brittle Transition Temperature DBTT

Excessive Laser power (keyhole porosity).

High scanning speed

High level of impurities

- High notch sensitivity

- High level of impurities

- Process conditions

- $\quad$ High cooling rates and thermal gradients

- $\quad$ High thermal fatigue

- $\quad$ High level of impurities

\section{Effect:}

- $\quad$ Poor powder layer spreading

- Low relative density

- Low Compressive strength

- High surface roughness

Effect:

- Poor tensile properties

- Poor thermal conductivity

\section{Solution:}

- Proper Feedstock selection

- Use spherical particle feedstock

Use smaller particle size

Minimize powder contaminants

Minimize the feedstock humidity

- Process optimization

Increase the laser power

Reduce the scanning speed

Minimize oxygen and other impurities

Use remelting scanning strategy

\section{Solution:}

- Process optimization

- $\quad$ Substrate preheating

- $\quad 67^{\circ}$ rotation scanning strategy

- Postprocess treatments

- Annealing

HIP

\section{Properties}

The main efforts in literature with regard to LPBF of unalloyed tungsten have been focused on achieving near-fully dense components with minimal microstructural defects. Other than density, only a few publications have reported properties such as surface roughness, wear resistance, friction coefficient, compressive strength, hardness, bending strength, and thermal conductivity.

Tan et al. [39] reported that unalloyed tungsten specimens produced by LPBF have higher hardness values (461-474 HV) compared to tungsten produced by traditional powder metallurgy methods (344-419 HV). The printed tungsten samples also showed ultimate compressive strength (933-1015 MPa) and compressive yield strength (791-882 MPa) that are comparable to tungsten produced by traditional powder metallurgy methods (780-1480 MPa and 750-1010 MPa). Similar findings were also reported by Wen et al. [37] and Guo et al. [43]. The aforementioned studies as well as other studies [34] also show consistent agreement between the increase of relative density and the improvement in ultimate 
compressive strength. SEM fractography of specimens also show typical brittle behavior in as-LPBF tungsten coupons as well as post-LPBF annealed coupons (Figure 24) [37,38,43].

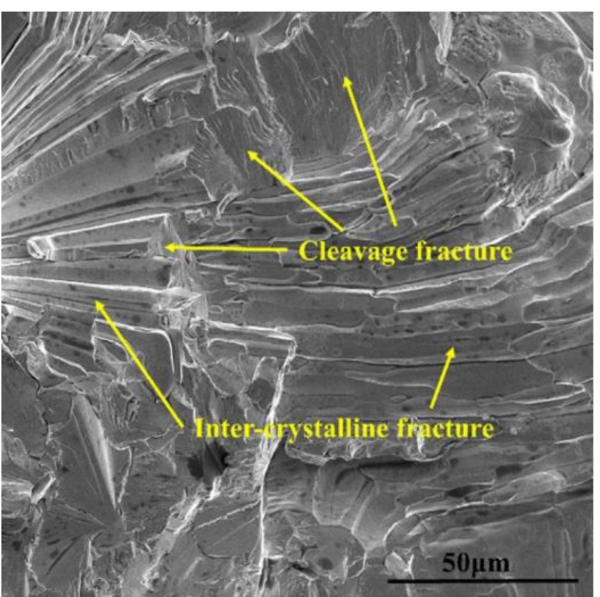

(a)

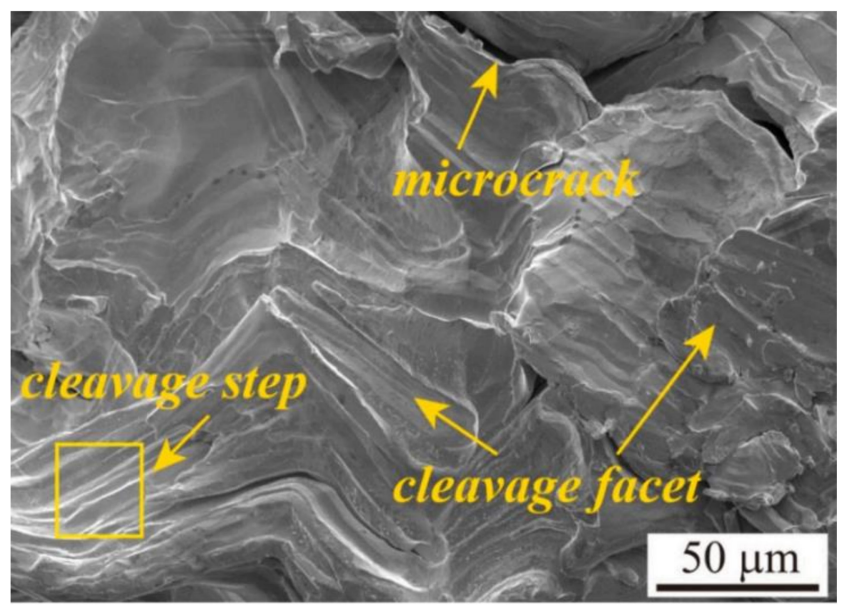

(b)

Figure 24. (a) Brittle fracture in as-LPBF tungsten (W) [37], (b) brittle fracture in post-LPBF annealed tungsten $(\mathrm{W})\left(2 \mathrm{~h}\right.$ annealing in vacuum at $\left.1100{ }^{\circ} \mathrm{C}\right)$ [38].

Xiong et al. [41] conducted three-point bending tests on unalloyed tungsten specimens $(5 \times 5 \times 35 \mathrm{~mm})$ made by PBF-L under different scanning speeds $(400 \mathrm{~mm} / \mathrm{s}, 500 \mathrm{~mm} / \mathrm{s}$ and $600 \mathrm{~mm} / \mathrm{s}$ ). Bending strength measurements correlated with the measured relative density, and a maximum bending strength of $131 \mathrm{MPa}$ was achieved at a maximum relative density of $98.1 \%$. The same study also examined the effect of laser remelting on surface roughness of pure tungsten specimens made by LPBF. They reported a surface roughness reduction of $28 \%$ after double remelting. The applied linear energy density $(p / v)$ for the layer remelting scan was set $50 \%$ higher than that of the powder melting scan.

Chen et al. [49] measured the thermal conductivity of unalloyed tungsten made by LPBF and reported a maximum value of $129 \mathrm{Wm}^{-1} \mathrm{~K}^{-1}$ and $146 \mathrm{Wm}^{-1} \mathrm{~K}^{-1}$ without and with post-process HIP, respectively. The measured thermal conductivity vs density values for as-LPBF coupons were also extrapolated in the study to estimate the maximum possible thermal conductivity at $100 \%$ relative density (Figure 25). The maximum possible thermal conductivity in as-LPBF tungsten specimens was however predicted to be around $140 \mathrm{Wm}^{-1} \mathrm{~K}^{-1}$, which is $20 \%$ less than that of theoretical pure tungsten $\left(173 \mathrm{Wm}^{-1} \mathrm{~K}^{-1}\right)[49,85]$. Table 4 summarizes the mechanical properties at maximum density that are reported in literature. In some cases, the optimum achievable value was found in specimens with lower densities than the maximum. In that case, the corresponding and maximum mechanical properties values are reported.

The presence of microstructural defects ultimately reflects on the measured properties of the printed components. With regard to unalloyed tungsten, the presence of microcracks and porosity can demote the tensile strength and compressive strength respectively. Other properties such as thermal conductivity and bending strength have been found affected by the presence of microcracks and porosity in unalloyed tungsten as well.

Depending on parameters such as the laser power, scanning speed/strategy, and the interrupted layer-by layer nature of LPBF, the buildup process of the product via powder bed fusion is usually associated with heterogeneous distribution of the developed thermal gradients and cooling rates, which reflects on the reported heterogeneity in grainsize distribution as well as properties such as the surface hardness. In a recent study by Zhou et al. [44], Vickers hardness tests were conducted along different planes of the tungsten coupons after LPBF. The reported hardness measurements in the study were found $\approx 14 \%$ lower on the XY plane as compared to the XZ/YZ planes (Figure 26). Such anisotropy in hardness measurements was attributed to the lower thermal gradients and higher stress 
relief along the XY plane (layer plane), resulting from the adopted zigzag scanning strategy and the partial remelting of each solid layer under the powder bed.

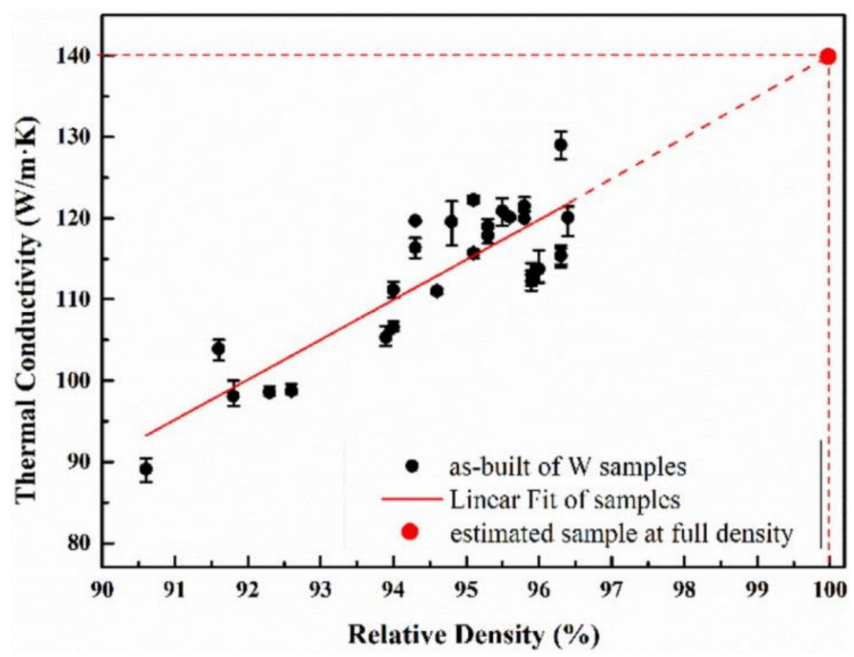

Figure 25. Thermal conductivity of tungsten (W) as measured vs relative density; the maximum extrapolated value of thermal conductivity at $100 \%$ density is $20 \%$ less than that of theoretical pure tungsten [49].

Table 4. Properties of unalloyed tungsten produced by LPBF.

\begin{tabular}{|c|c|c|c|c|c|c|c|c|}
\hline $\begin{array}{c}\text { Ultimate } \\
\text { Compressive } \\
\text { Strength (MPa) }\end{array}$ & $\begin{array}{c}\text { Yield } \\
\text { Compressive } \\
\text { Strength (MPa) }\end{array}$ & $\begin{array}{c}\text { Bending } \\
\text { Strength } \\
\text { (MPa) }\end{array}$ & $\begin{array}{c}\text { Hardness } \\
\text { (HV) }\end{array}$ & $\begin{array}{c}\text { Surface } \\
\text { Roughness, } \\
\text { Ra }(\mu \mathrm{m})\end{array}$ & $\begin{array}{l}\text { Coefficient } \\
\text { of Friction }\end{array}$ & $\begin{array}{c}\text { Wear } \\
\text { Resistance } \\
\mathrm{mm}^{3} /(\mathrm{N} \mathrm{m})\end{array}$ & $\begin{array}{c}\text { Thermal } \\
\text { Conductivity } \\
W /(m \cdot K)\end{array}$ & Ref. \\
\hline 1523 & 1067 & - & 428 & - & - & - & - & [37] \\
\hline - & - & - & 407 & - & - & - & - & [36] \\
\hline 1007 & - & - & - & - & - & - & - & [38] \\
\hline 1015 & 882 & - & $\begin{array}{c}461 \\
467^{1}\end{array}$ & 6.74 & - & - & - & [39] \\
\hline 1200 & $\begin{array}{c}1100 \\
1197^{1}\end{array}$ & 131 & 456 & $\begin{array}{c}14.72^{1} \\
10.62^{1}\end{array}$ & - & - & - & [41] \\
\hline 902 & - & - & 474 & - & 0.45 & $1.3 \times 10^{-5}$ & - & [43] \\
\hline- & - & - & - & - & - & - & $146^{2}$ & [47] \\
\hline 982 & - & - & 370 & - & - & - & - & [44] \\
\hline- & - & - & - & - & - & - & 150 & [86] \\
\hline 920 & & & 480 & & & & & [87] \\
\hline
\end{tabular}

${ }^{1}$ Not at maximum density. ${ }^{2}$ With post-process HIP.

Another aspect of the relation between microstructure and mechanical properties is the induced grains shape/directionality as discussed in the previous section. The same study by Zhou et al. [44] has shown $4 \%$ increase in compressibility when similar tungsten coupons were pressed along the vertical build direction (grains columnar direction), as compared to the horizontal direction. The test coupons have also experienced clear deformation/tearing and trans-granular fracture across the columnar grains when compressed along the build direction (Figure 26). The compressive strength of dense coupons however was found less dependent on grains orientation $(\approx 0.6 \%$ difference between vertical and horizontal directions). 


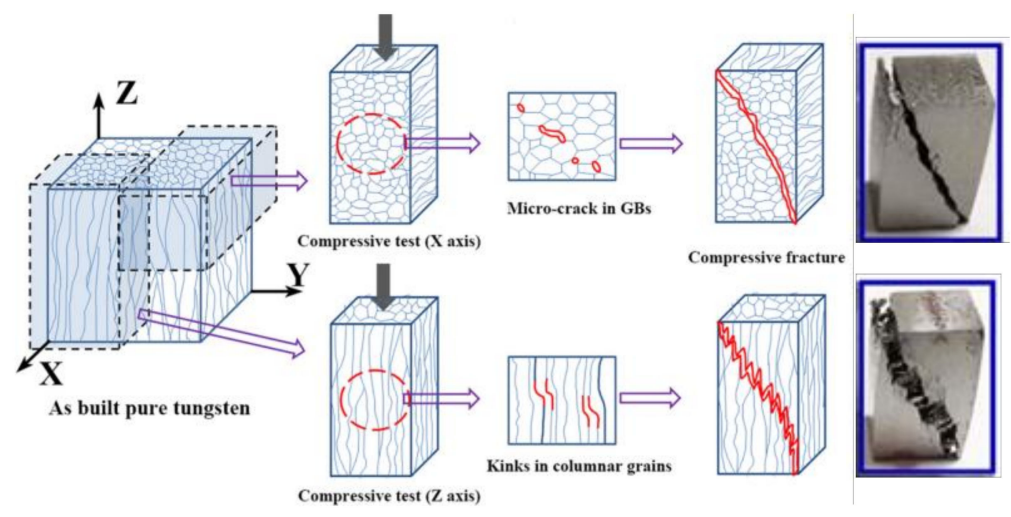

Figure 26. Fracture behavior under compression along different directions [83].

\section{Summary and Outlook}

This review presented the state-of-the-art in selective laser melting of unalloyed tungsten by laser powder bed fusion LPBF, with a focus on the effect of process parameters on the developed structure and properties.

The successful implementation of LPBF technology as a substitute of traditional tungsten manufacturing techniques can significantly improve the design flexibility and consequently improve the product performance and cost. Such potential has been demonstrated by the commercialization of 3D-printed tungsten 2D anti-scatter grids that were developed to substitute the less efficient and labor costly 1D grids in medical imaging systems [88]. In addition to the medical sector, other sectors such as aerospace, defense, and energy are expected to benefit from the production of unalloyed tungsten by LPBF. The foreseen research directions in such sectors include the development of single-piece thrusters for space propulsion systems as well as single-piece high heat flux exchanges for nuclear reactors [89]. The following points highlight the main findings in this topic and suggest topics that could be addressed in future work:

- Unalloyed tungsten has been successfully produced by LPBF with up to $98.71 \%$ of theoretical density without post-process densification.

- The recommended tungsten feedstock characteristics for high density are spherical powder particles with D10 $=9-10 \mu \mathrm{m}, \mathrm{D} 50=14-17 \mu \mathrm{m}, \mathrm{D} 90=23-25 \mu \mathrm{m}$.

- Spherical tungsten powder possesses higher flowability and packing density as compared to faceted irregular powder.

- Numerical studies have shown inverse correlation between powder particle size and the powder absorption of laser energy.

- The LPBF processing window based on literature for high-density unalloyed tungsten is laser power between $200 \mathrm{~W}$ and $400 \mathrm{~W}$, scanning speed between $200 \mathrm{~mm} / \mathrm{s}$ and $400 \mathrm{~mm} / \mathrm{s}$, layer thickness between $0.02 \mathrm{~mm}$ and $0.03 \mathrm{~mm}$, and hatch distance between 0.08 and $0.1 \mathrm{~mm}$.

- The recommended volumetric energy densities based on the literature range between $300 \mathrm{~J} / \mathrm{mm}^{3}$ and $350 \mathrm{~J} / \mathrm{mm}^{3}$.

- The expected properties of as-LPBF tungsten (W) include compressive strength of $1523 \mathrm{MPa}$, yield compressive strength of $1197 \mathrm{MPa}$, hardness of $474 \mathrm{HV}$, bending strength of $131 \mathrm{Mpa}$, and thermal conductivity of $129 \mathrm{Wm}^{-1} \mathrm{~K}^{-1}$.

- Micro-cracks still present a problem in as-LPBF tungsten and could be reduced partially by substrate preheating, hot isostatic pressing, and annealing.

- Laser remelting can significantly improve the surface roughness but can unfavorably promote thermal fatigue crack growth in tungsten.

- HIP after LPBF can cause a minor increase in part densification $(0.5 \%)$ and a much noticeable increase in thermal conductivity (13\%).

- Relative density above $98 \%$ could be achieved at lower volumetric energy densities with the aid of substrate preheating $\left(170 \mathrm{~J} / \mathrm{mm}^{3}\right.$ and $1273 \mathrm{~K}$ preheating). 
- Further work is needed to understand the effect of process parameters on part distortion, residual stresses, and spatter formation.

- The evolution of microstructure and bond strength at the substrate/coupon interface when printing tungsten on different substrate material is not discussed in detail in the literature.

- Very limited research has been done on the influence of post processing on mechanical properties.

- To the best of the present authors' knowledge, properties such as tensile, fatigue, fracture toughness, and impact strength of unalloyed tungsten after LPBF have not been identified in the open literature.

- 3D-printed tungsten anti-scatter grids have been successfully developed and commercialized for medical imaging systems.

- A successful production of tungsten via LPBF will significantly subserve in medical, aerospace, defense, and energy applications.

- The future perspective of the present research topic includes utilization of LPBF technology to produce single-piece tungsten heat exchangers for high heat flux applications as well as single-piece rocket thrusters for space exploration and defense systems.

- Another prospective idea for the present research topic includes the production of WEurofer bi-materials via LPBF for first wall applications in future fusion reactors $[90,91]$.

Author Contributions: Writing—original draft preparation, M.S.S.; writing—review and editing, P.K. and M.A.E. All authors have read and agreed to the published version of the manuscript.

Funding: This research received no external funding.

Institutional Review Board Statement: Not applicable.

Informed Consent Statement: Not applicable.

Data Availability Statement: Not applicable.

Conflicts of Interest: The authors declare no conflict of interest.

\section{References}

1. Norajitra, P.; Giniyatulin, R.; Hirai, T.; Krauss, W.; Kuznetsov, V.; Mazul, I.; Ovchinnikov, I.; Reiser, J.; Ritz, G.; Ritzhaupt-Kleissl, H.-J.; et al. Current status of He-cooled divertor development for DEMO. Fusion Eng. Des. 2009, 84, 1429-1433. [CrossRef]

2. Liu, C.-L.; Zhang, J.; Yang, H.; Li, L.; Wang, Z.-L.; Liang, C.; Zhou, Z.-B.; Cao, L.; Yao, D.-M.; Gao, X. The Temperature Control Mechanism of a Breeding Blanket Module for Fusion Reactor. J. Fusion Energy 2014, 33, 422-427. [CrossRef]

3. Federici, G.; Boccaccini, L.; Cismondi, F.; Gasparotto, M.; Poitevin, Y.; Ricapito, I. An overview of the EU breeding blanket design strategy as an integral part of the DEMO design effort. Fusion Eng. Des. 2019, 141, 30-42. [CrossRef]

4. Youchison, D.; Lutz, T.; Williams, B.; Nygren, R. High heat flux testing of a helium-cooled tungsten tube with porous foam. Fusion Eng. Des. 2007, 82, 1854-1860. [CrossRef]

5. Nygren, R.E.; Youchison, D.L. Testing of Tungsten and Tungsten-Armored Heat Sinks for Fusion Applications; No. SAND2008-5803C; Sandia National Lab. (SNL-NM): Albuquerque, NM, USA, 2008.

6. Sharafat, S.; Aoyama, A.; Narula, M.; El-Awady, J.; Ghoniem, N.; Williams, B.; Youchison, D. Development Status of the HeliumCooled Porous Tungsten Heat Exchanger Concept. In 2007 IEEE 22nd Symposium on Fusion Engineering; IEEE: New York, NY, USA, 2007; pp. 1-4. [CrossRef]

7. Caccia, M.; Tabandeh-Khorshid, M.; Itskos, G.; Strayer, A.R.; Caldwell, A.S.; Pidaparti, S.; Singnisai, S.; Rohskopf, A.D.; Schroeder, A.M.; Jarrahbashi, D.; et al. Ceramic-metal composites for heat exchangers in concentrated solar power plants. Nature 2018, 562, 406-409. [CrossRef]

8. US6779462B2-Kinetic Energy Rod Warhead with OPTIMAL PENETRATORS—Google Patents. Available online: https:// patents.google.com/patent/US6779462 (accessed on 31 March 2021).

9. Philipps, V. Tungsten as material for plasma-facing components in fusion devices. J. Nucl. Mater. 2011, 415, S2-S9. [CrossRef]

10. Lassner, E.; Schubert, W.-D. Tungsten; Springer Science and Business Media LLC: Vienna, Austria, $1999 ;$ pp. $124-125$.

11. Nie, B.; Yang, L.; Huang, H.; Bai, S.; Wan, P.; Liu, J. Femtosecond laser additive manufacturing of iron and tungsten parts. Appl. Phys. A 2015, 119, 1075-1080. [CrossRef]

12. Seltzer, S. Tables of X-ray Mass Attenuation Coefficients and Mass Energy-Absorption Coefficients; National Institute of Standards and Technology-PL: Gaithersburg, MD, USA, 1995. 
13. Sayyed, M.I.; Almatari, M. Radiation Shielding Investigation of Lead Borophosphate Glasses Modified by Tungsten Oxide. J. Test. Eval. 2018, 48, 3734-3741. [CrossRef]

14. Shen, T.; Dai, Y.; Lee, Y. Microstructure and tensile properties of tungsten at elevated temperatures. J. Nucl. Mater. 2016, 468, 348-354. [CrossRef]

15. Deprez, K.; Vandenberghe, S.; Van Audenhaege, K.; Van Vaerenbergh, J.; Van Holen, R. Rapid additive manufacturing of MR compatible multipinhole collimators with selective laser melting of tungsten powder. Med. Phys. 2012, 40, 012501. [CrossRef]

16. Kurishita, H.; Matsuo, S.; Arakawa, H.; Sakamoto, T.; Kobayashi, S.; Nakai, K.; Okano, H.; Watanabe, H.; Yoshida, N.; Torikai, Y.; et al. Current status of nanostructured tungsten-based materials development. Phys. Scr. 2014, T159, 014032. [CrossRef]

17. Wurster, S.; Baluc, N.; Battabyal, M.; Crosby, T.; Du, J.; García-Rosales, C.; Hasegawa, A.; Hoffmann, A.; Kimura, A.; Kurishita, H.; et al. Recent progress in R\&D on tungsten alloys for divertor structural and plasma facing materials. J. Nucl. Mater. 2013, 442, S181-S189. [CrossRef]

18. Sidambe, A.; Judson, D.; Colosimo, S.; Fox, P. Laser powder bed fusion of a pure tungsten ultra-fine single pinhole collimator for use in gamma ray detector characterisation. Int. J. Refract. Met. Hard Mater. 2019, 84, 104998. [CrossRef]

19. Mullendore, J. Tungsten: Its Manufacture, Properties, and Application. In Refractory Metals and Their Industrial Applications; ASTM International: West Conshohocken, PA, USA, 1984; p. 82.

20. Rieck, G.D. Tungsten and Its Compounds; Elsevier: Amsterdam, The Netherlands, 2013; ISBN 978-1-4832-0108-5.

21. Trasorras, J.R.L.; Wolfe, T.A.; Knabl, W.; Venezia, C.; Lemus, R.; Lassner, E.; Schubert, W.-D.; Lüderitz, E.; Wolf, H.-U. Tungsten, Tungsten Alloys, and Tungsten Compounds. Ullmann's Encycl. Ind. Chem. 2016, 37, 1-53. [CrossRef]

22. ASTM. ISO/ASTM 52900: 2015 Additive Manufacturing-General Principles-Terminology; ASTM F2792-10e1; ASTM International: West Conshohocken, PA, USA, 2012.

23. Li, K.-L.; Chen, J.-H.; Zhao, C.-C.; Shen, Z.-J.; Liu, W. A review of tungsten fabricated via laser powder bed fusion. Tungsten 2021, 3, 218-233. [CrossRef]

24. Gibson, I.; Rosen, D.; Stucker, B.; Khorasani, M. Additive Manufacturing Technologies; Springer International Publishing: Cham, Switzerland, 2021; Volume 17.

25. Ghasemi, A.; Fereiduni, E.; Balbaa, M.; Jadhav, S.D.; Elbestawi, M.; Habibi, S. Influence of Alloying Elements on Laser Powder Bed Fusion Processability of Aluminum: A New Insight into the Oxidation Tendency. Addit. Manuf. 2021, 46, 102145. [CrossRef]

26. Yakout, M.; Cadamuro, A.; Elbestawi, M.A.; Veldhuis, S.C. The selection of process parameters in additive manufacturing for aerospace alloys. Int. J. Adv. Manuf. Technol. 2017, 92, 2081-2098. [CrossRef]

27. Zhang, D.; Cai, Q.; Liu, J. Formation of Nanocrystalline Tungsten by Selective Laser Melting of Tungsten Powder. Mater. Manuf. Process. 2012, 27, 1267-1270. [CrossRef]

28. Ebert, R.; Ullmann, F.; Hildebrandt, D.; Schille, J.; Hartwig, L.; Kloetzer, S.; Streek, A.; Exner, H. Laser processing of tungsten powder with femtosecond laser radiation. J. Laser Micro Nanoeng. 2012, 7, 38. [CrossRef]

29. Zhou, X.; Liu, X.; Zhang, D.; Shen, Z.; Liu, W. Balling phenomena in selective laser melted tungsten. J. Mater. Process. Technol. 2015, 222, 33-42. [CrossRef]

30. Zhang, J.; Gu, D.; Yang, Y.; Zhang, H.; Chen, H.; Dai, D.; Lin, K. Influence of Particle Size on Laser Absorption and Scanning Track Formation Mechanisms of Pure Tungsten Powder During Selective Laser Melting. Engineering 2019, 5, 736-745. [CrossRef]

31. Wang, L.-Z.; Wu, J.-J.; Zhang, D.-J. Properties evolution of additive manufacture used tungsten powders prepared by radio frequency induction plasma. Int. J. Refract. Met. Hard Mater. 2017, 67, 90-97. [CrossRef]

32. Zi, X.; Chen, C.; Wang, X.; Wang, P.; Zhang, X.; Zhou, K. Spheroidisation of tungsten powder by radio frequency plasma for selective laser melting. Mater. Sci. Technol. 2018, 34, 735-742. [CrossRef]

33. Wang, D.; Wang, Z.; Li, K.; Ma, J.; Liu, W.; Shen, Z. Cracking in laser additively manufactured W: Initiation mechanism and a suppression approach by alloying. Mater. Des. 2019, 162, 384-393. [CrossRef]

34. Wang, D.; Yu, C.; Zhou, X.; Ma, J.; Liu, W.; Shen, Z. Dense Pure Tungsten Fabricated by Selective Laser Melting. Appl. Sci. 2017, 7, 430. [CrossRef]

35. Field, A.C.; Carter, L.N.; Adkins, N.J.E.; Attallah, M.M.; Gorley, M.J.; Strangwood, M. The Effect of Powder Characteristics on Build Quality of High-Purity Tungsten Produced via Laser Powder Bed Fusion (LPBF). Met. Mater. Trans. A 2020, 51, 1367-1378. [CrossRef]

36. Gokcekaya, O.; Ishimoto, T.; Todo, T.; Wang, P.; Nakano, T. Influence of powder characteristics on densification via crystallographic texture formation: Pure tungsten prepared by laser powder bed fusion. Addit. Manuf. Lett. 2021, 1, 100016. [CrossRef]

37. Wen, S.; Wang, C.; Zhou, Y.; Duan, L.; Wei, Q.; Yang, S.; Shi, Y. High-density tungsten fabricated by selective laser melting: Densification, microstructure, mechanical and thermal performance. Opt. Laser Technol. 2019, 116, 128-138. [CrossRef]

38. Ren, X.; Liu, H.; Lu, F.; Huang, L.; Yi, X. Effects of processing parameters on the densification, microstructure and mechanical properties of pure tungsten fabricated by optimized selective laser melting: From single and multiple scan tracks to bulk parts. Int. J. Refract. Met. Hard Mater. 2021, 96, 105490. [CrossRef]

39. Tan, C.; Zhou, K.; Ma, W.; Attard, B.; Zhang, P.; Kuang, T. Selective laser melting of high-performance pure tungsten: Parameter design, densification behavior and mechanical properties. Sci. Technol. Adv. Mater. 2018, 19, 370-380. [CrossRef] [PubMed]

40. Müller, A.V.; Schlick, G.; Neu, R.; Anstätt, C.; Klimkait, T.; Lee, J.; Pascher, B.; Schmitt, M.; Seidel, C. Additive manufacturing of pure tungsten by means of selective laser beam melting with substrate preheating temperatures up to $1000^{\circ} \mathrm{C}$. Nucl. Mater. Energy 2019, 19, 184-188. [CrossRef] 
41. Xiong, Z.; Zhang, P.; Tan, C.; Dong, D.; Ma, W.; Yu, K. Selective Laser Melting and Remelting of Pure Tungsten. Adv. Eng. Mater. 2020, 22, 1901352. [CrossRef]

42. Li, J.; Wu, Y.; Zhou, B.; Wei, Z. Laser Powder Bed Fusion of Pure Tungsten: Effects of Process Parameters on Morphology, Densification, Microstructure. Materials 2020, 14, 165. [CrossRef]

43. Guo, M.; Gu, D.; Xi, L.; Zhang, H.; Zhang, J.; Yang, J.; Wang, R. Selective laser melting additive manufacturing of pure tungsten: Role of volumetric energy density on densification, microstructure and mechanical properties. Int. J. Refract. Met. Hard Mater. 2019, 84, 105025. [CrossRef]

44. Zhou, K.; Chen, W.; Yang, Y.; Li, R.; Dong, L.; Fu, Y.-Q. Microstructure and mechanical behavior of porous tungsten skeletons synthesized by selected laser melting. Int. J. Refract. Met. Hard Mater. 2021, 103, 105769. [CrossRef]

45. Todo, T.; Ishimoto, T.; Gokcekaya, O.; Oh, J.; Nakano, T. Single crystalline-like crystallographic texture formation of pure tungsten through laser powder bed fusion. Scr. Mater. 2021, 206, 114252. [CrossRef]

46. Balbaa, M.; Ghasemi, A.; Fereiduni, E.; Elbestawi, M.; Jadhav, S.; Kruth, J.-P. Role of powder particle size on laser powder bed fusion processability of AlSi10mg alloy. Addit. Manuf. 2021, 37, 101630. [CrossRef]

47. Braun, J.; Kaserer, L.; Stajkovic, J.; Leitz, K.-H.; Tabernig, B.; Singer, P.; Leibenguth, P.; Gspan, C.; Kestler, H.; Leichtfried, G. Molybdenum and tungsten manufactured by selective laser melting: Analysis of defect structure and solidification mechanisms Int. J. Refract. Met. Hard Mater. 2019, 84, 104999. [CrossRef]

48. Sidambe, A.; Tian, Y.; Prangnell, P.; Fox, P. Effect of processing parameters on the densification, microstructure and crystallographic texture during the laser powder bed fusion of pure tungsten. Int. J. Refract. Met. Hard Mater. 2019, 78, 254-263. [CrossRef]

49. Chen, J.; Li, K.; Wang, Y.; Xing, L.; Yu, C.; Liu, H.; Ma, J.; Liu, W.; Shen, Z. The effect of hot isostatic pressing on thermal conductivity of additively manufactured pure tungsten. Int. J. Refract. Met. Hard Mater. 2020, 87, 105135. [CrossRef]

50. Seyam, M.S.; Shazly, M.; El-Mokadem, A.; Wifi, A.S. A binding scheme to minimize thinning of formed tailor welded blanks. Int J. Adv. Manuf. Technol. 2018, 96, 3933-3950. [CrossRef]

51. Das, S. On some physical aspects of process control in direct selective laser sintering of metals part I. In 2001 International Solid Freeform Fabrication Symposium; The University of Texas at Austin: Austin, TX, USA, 2001. [CrossRef]

52. Lampman, S. (Ed.) Weld Integrity and Performance: A Source Book Adapted from ASM International Handbooks, Conference Proceedings, and Technical Books; ASM International: Novelty, OH, USA, 1997; ISBN1 1615032045. ISBN2 9781615032044.

53. Wang, D.; Li, K.; Yu, C.; Ma, J.; Liu, W.; Shen, Z. Cracking behavior in additively manu-factured pure tungsten. Acta Metall. Sin. Engl. Lett. 2019, 32, 127-135. [CrossRef]

54. Huang, J.; Li, M.; Wang, J.; Pei, Z.; Mclntyre, P.; Ma, C. Selective laser melting of tungsten: Effects of hatch distance and point distance on pore formation. J. Manuf. Process. 2021, 61, 296-302. [CrossRef]

55. Aversa, A.; Moshiri, M.; Librera, E.; Hadi, M.; Marchese, G.; Manfredi, D.; Lorusso, M.; Calignano, F.; Biamino, S.; Lombardi, M.; et al. Single scan track analyses on aluminium based powders. J. Mater. Process. Technol. 2018, 255, 17-25. [CrossRef]

56. Yadroitsev, I.; Gusarov, A.; Yadroitsava, I.; Smurov, I. Single track formation in selective laser melting of metal powders. J. Mater Process. Technol. 2010, 210, 1624-1631. [CrossRef]

57. Yueling, G.U.O.; Lina, J.I.A.; Bin, K.O.N.G.; Na, W.A.N.G.; Zhang, H. Single track and single layer formation in selective laser melting of niobium solid solution alloy. Chin. J. Aeronaut. 2018, 31, 860-866.

58. Kruth, J.-P.; Levy, G.; Klocke, F.; Childs, T.H.C. Consolidation phenomena in laser and powder-bed based layered manufacturing. CIRP Ann. 2007, 56, 730-759. [CrossRef]

59. Xie, Y.-J.; Yang, H.-C.; Wang, X.-B.; Zhao, L.; Kuang, C.-J.; Han, W. Control of wall thickness and surface morphology of tungsten thin wall parts by adjusting selective laser melting parameters. J. Iron Steel Res. Int. 2019, 26, 182-190. [CrossRef]

60. Vrancken, B.; Ganeriwala, R.K.; Matthews, M.J. Analysis of laser-induced microcracking in tungsten under additive manufacturing conditions: Experiment and simulation. Acta Mater. 2020, 194, 464-472. [CrossRef]

61. Childs, T.H.C.; Hauser, C.; Badrossamay, M. Selective laser sintering (melting) of stainless and tool steel powders: Experiments and modelling. Proc. Inst. Mech. Eng. Part B J. Eng. Manuf. 2005, 219, 339-357. [CrossRef]

62. Kruth, J.; Froyen, L.; Rombouts, M.; Van Vaerenbergh, J.; Mercells, P. New Ferro Powder for Selective Laser Sintering of Dense Parts. CIRP Ann. 2003, 52, 139-142. [CrossRef]

63. Rombouts, M.; Froyen, L.; Kruth, J.-P.; Van Vaerenbergh, J.; Mercelis, P. Production and properties of dense iron based parts produced by laser melting with plasma formation. In Proceedings of the Powder Metallurgy World Congress, Vienna, Austria, 1 October 2004; Volume 5, pp. 115-121, ISBN 1-899072-15-2.

64. Stephens, J.R. Review of Deformation Behavior of Tungsten at Temperature Less Than 0.2 Absolute Melting Temperature; No. NASA-TMX-2482; NTRS-NASA: Washington, DC, USA, 1 January 1972.

65. Iveković, A.; Omidvari, N.; Vrancken, B.; Lietaert, K.; Thijs, L.; Vanmeensel, K.; Vleugels, J.; Kruth, J.-P. Selective laser melting of tungsten and tungsten alloys. Int. J. Refract. Met. Hard Mater. 2018, 72, 27-32. [CrossRef]

66. Ren, C.; Fang, Z.; Koopman, M.; Butler, B.; Paramore, J.; Middlemas, S. Methods for improving ductility of tungsten-A review. Int. J. Refract. Met. Hard Mater. 2018, 75, 170-183. [CrossRef]

67. Xu, A.; Beck, C.; Armstrong, D.E.; Rajan, K.; Smith, G.D.; Bagot, P.A.; Roberts, S.G. Ion-irradiation-induced clustering in W-Re and W-Re-Os alloys: A comparative study using atom probe tomography and nanoindentation measurements. Acta Mater. 2015, 87, 121-127. [CrossRef] 
68. Rieth, M.; Boutard, J.; Dudarev, S.; Ahlgren, T.; Antusch, S.; Baluc, N.; Barthe, M.-F.; Becquart, C.; Ciupinski, L.; Correia, J.; et al. Review on the EFDA programme on tungsten materials technology and science. J. Nucl. Mater. 2011, 417, 463-467. [CrossRef]

69. Xie, Z.; Zhang, T.; Liu, R.; Fang, Q.; Miao, S.; Wang, X.; Liu, C. Grain growth behavior and mechanical properties of zirconium micro-alloyed and nano-size zirconium carbide dispersion strengthened tungsten alloys. Int. J. Refract. Met. Hard Mater. 2015, 51, 180-187. [CrossRef]

70. Bhattarai, J.; Akiyama, E.; Habazaki, H.; Kawashima, A.; Asami, K.; Hashimoto, K. The influence of concentration of hydrochloric acid solutions on the passivation behavior of sputter-deposited tungsten rich W-Nb alloys. Corros. Sci. 1998, 40, 1897-1914. [CrossRef]

71. Arshad, K.; Zhao, M.-Y.; Yuan, Y.; Zhang, Y.; Zhao, Z.-H.; Wang, B.; Zhou, Z.-J.; Lu, G.-H. Effects of vanadium concentration on the densification, microstructures and mechanical properties of tungsten vanadium alloys. J. Nucl. Mater. 2014, 455, 96-100. [CrossRef]

72. Tanabe, T.; Eamchotchawalit, C.; Busabok, C.; Taweethavorn, S.; Fujitsuka, M.; Shikama, T. Temperature dependence of thermal conductivity in W and W-Re alloys from 300 to $1000 \mathrm{~K}$. Mater. Lett. 2003, 57, 2950-2953. [CrossRef]

73. Xie, Z.; Liu, R.; Miao, S.; Yang, X.D.; Zhang, T.; Wang, X.P.; Fang, Q.F.; Liu, C.S.; Luo, G.N.; Lian, Y.Y.; et al. Extraordinary high ductility/strength of the interface designed bulk W-ZrC alloy plate at relatively low temperature. Sci. Rep. 2015, 5, 16014. [CrossRef]

74. Tejado, E.; Carvalho, P.; Munoz, A.; Dias, M.; Correia, J.B.; Mardolcar, U.; Pastor, J.Y. The effects of tantalum addition on the microtexture and mechanical behaviour of tungsten for ITER applications. J. Nucl. Mater. 2015, 467, 949-955. [CrossRef]

75. Pintsuk, G.; Kurishita, H.; Linke, J.; Arakawa, H.; Matsuo, S.; Sakamoto, T.; Kobayashi, S.; Nakai, K. Thermal shock response of fine- and ultra-fine-grained tungsten-based materials. Phys. Scr. 2011, T145, 014060. [CrossRef]

76. Wurster, S.; Gludovatz, B.; Hoffmann, A.; Pippan, R. Fracture behaviour of tungsten-vanadium and tungsten-tantalum alloys and composites. J. Nucl. Mater. 2011, 413, 166-176. [CrossRef]

77. Garfinkle, M.; Witzke, R.W.; Klopp, W.D. Superplasticity in Tungsten-Rhenium Alloys; National Aeronautics and Space Administration: Washington, DC, USA, 1 August 1968; Volume 4728.

78. Arshad, K.; Yuan, Y.; Cheng, L.; Wang, J.; Zhou, Z.-J.; De Temmerman, G.; Lu, G.-H. Deuterium blistering in tungsten and tungsten vanadium alloys. Fusion Eng. Des. 2016, 107, 25-31. [CrossRef]

79. Gu, D.; Dai, D.; Chen, W.; Chen, H. Selective Laser Melting Additive Manufacturing of Hard-to-Process Tungsten-Based Alloy Parts with Novel Crystalline Growth Morphology and Enhanced Performance. J. Manuf. Sci. Eng. 2016, 138, 081003. [CrossRef]

80. Li, K.; Ma, G.; Xing, L.; Wang, Y.; Yu, C.; Chen, J.; Ma, J.; Wu, G.; Liu, W.; Shen, Z.; et al. Crack suppression via in-situ oxidation in additively manufactured W-Ta alloy. Mater. Lett. 2020, 263, 127212. [CrossRef]

81. Li, K.; Li, Y.; Chen, W.; Zhao, C.; Yuan, Y.; Cheng, L.; Morgan, T.; Liu, W.; Shen, Z. Effect of Ta addition on the fuzz formation of additively manufactured W-based materials. Nucl. Fusion 2020, 60, 064004. [CrossRef]

82. Li, K.; Wang, D.; Xing, L.; Wang, Y.; Yu, C.; Chen, J.; Zhang, T.; Ma, J.; Liu, W.; Shen, Z. Crack suppression in additively manufactured tungsten by introducing secondary-phase nanoparticles into the matrix. Int. J. Refract. Met. Hard Mater. 2019, 79, 158-163. [CrossRef]

83. Hu, Z.; Zhao, Y.; Guan, K.; Wang, Z.; Ma, Z. Pure tungsten and oxide dispersion strengthened tungsten manufactured by selective laser melting: Microstructure and cracking mechanism. Addit. Manuf. 2020, 36, 101579. [CrossRef]

84. Liu, K.; Gu, D.; Guo, M.; Sun, J. Effects of processing parameters on densification behavior, microstructure evolution and mechanical properties of W-Ti alloy fabricated by laser powder bed fusion. Mater. Sci. Eng. A 2021, 829, 142177. [CrossRef]

85. Bai, S.; Liu, J.; Yang, P.; Huang, H.; Yang, L.-M. Femtosecond fiber laser additive manufacturing of tungsten. In Optical Pattern Recognition IX; SPIE: Washington, DC, USA, 6 April 2016; Volume 9738, p. 97380U-.

86. Abbas, M.A.; Anru, Y.; Wang, Z.Y. Micro-Structural characteristics of Additively Manufactured Pure Tungsten; IOP Publishing England: Bristol, UK, 2021; Volume 635, p. 012014.

87. Abbas, M.; Anru, Y.; Wang, Z. On the Use of EBSD and Microhardness to Study the Microstructure Properties of Tungsten Samples Prepared by Selective Laser Melting. Materials 2021, 14, 1215. [CrossRef]

88. Anti X-ray Scatter Grids I DUNLEE I Radiographic Grids. (n.d.). Retrieved 22 January 2022. Available online: https://www. dunlee.com/a-w/3d-metal-printing/our-offer/anti-scatter-grids-for-ct.html (accessed on 22 January 2022).

89. Kinefuchi, K.; Nakata, D.; Coral, G.; Suyalatu; Sakai, H.; Tsukizaki, R.; Nishiyama, K. Additive-manufactured single-piece thin multi-layer tungsten heater for an electrothermal thruster. Rev. Sci. Instrum. 2021, 92, 114501. [CrossRef]

90. de Prado, J.; Sánchez, M.; Wirtz, M.; Pintsuk, G.; Du, J.; Linke, J.; Ureña, A. High heat flux performance of W-Eurofer brazed joints. J. Nucl. Mater. 2018, 499, 225-232. [CrossRef]

91. de Prado, J.; Sal, E.; Sánchez, M.; García-Rosales, C.; Ureña, A. Microstructural and mechanical characterization of self-passivating W-Eurofer joints processed by brazing technique. Fusion Eng. Des. 2021, 169, 112496. [CrossRef] 